\title{
Water-energy and GHG nexus assessment of alternative heat recovery options in industries: a case study on electric steelmaking in Europe.
}

\author{
Damiana Chinese*, Maurizio Santin, Onorio Saro \\ Dipartimento Politecnico di Ingegneria e Architettura \\ University of Udine \\ *damiana.chinese@uniud.it
}

\begin{abstract}
In the last few years, the water-energy nexus concept has emerged as a global issue in the international research community. However, studies on European countries are relatively few, and often focused on the energy sector and agriculture, even though industry dominates water use in many European countries. Cooling purposes represent the main part of industrial water demand, and waste heat recovery is perceived as a main strategy to improve industrial resource efficiency. In this paper, we consider a real case study of low-temperature waste-heat recovery in an electric steelmaking industry and evaluate the impact of feasible interventions on primary energy and water consumption, as well as on $\mathrm{CO}_{2}$ equivalent emissions. Based on a Europe wide review of energy and water prices, of energy sources and corresponding resource efficiency indicators, a Monte Carlo model was developed to undertake a generalization of the case study to the EU-15. It was found that, in spite of common intuition, solutions with the lowest primary energy demand and the lowest $\mathrm{CO}_{2}$ equivalent emissions demonstrate the greatest water footprint. This is especially the case of southern European countries, where heat recovery projects with the highest water intensity are economically feasible due to high electricity and low water prices. As increasing carbon prices may exacerbate this phenomenon, inducing a switch to more water intensive technologies, policy instruments for supporting industrial energy efficiency or carbon emission reduction should be carefully designed.
\end{abstract}

\section{KEYWORDS}

Water-energy nexus, industrial cooling systems, absorption cooling, ORC, water footprint of electricity generation 


\section{INTRODUCTION}

The interdependencies between water and energy requirements have been long recognized in the international scientific community [1] and in policy making, especially in the US [2]. Following the Bonn Nexus Conference in 2011 [3], the water energy nexus has come into focus also in Europe, and an increasing body of research was developed globally to integrate the traditionally separate issues of water and energy across the spectrum of policy, planning, design and operation [4].

The evaluation of the water intensity of the energy sector, from fuel extraction to energy conversion and distribution, and of the energy intensity of the water sector, including production, distribution and wastewater management, have represented the core of nexus research until now [5]. Empirical and model based studies have been performed for individual countries, among others for the US [6,7], China [8,9], Middle East and North Africa [10], Brazil [11], Thailand [12].

European studies are relatively few and their focus is more shifted onto agriculture and food production, in the framework of the expanded water-energy-food nexus concept discussed within the Bonn Conference [13]. Some studies concerning Spain and Germany are mentioned in a literature review concerning energy consumption for water use cycles [14], while a consumptive water footprint of electricity and heat was presented at an aggregated European level in [15]. However, water footprints of electricity for individual European countries could not be retrieved in literature.

Furthermore, although manufacturing is one of the sectors where the greatest increases in water consumption are expected in future [16], the literature on water energy nexus contains just a few studies focusing on industries other than electricity generation. A recent work by [17] uses input-output analysis to investigate the nexus between water saving and energy conservation for the Chinese industrial sector as a whole. At the operational level of single industries and factories, a framework for extending the energy diagnosis and management approaches of the ISO 50001 standard to industrial water management was recently proposed in [18]. Varbanov [19] underlines that the explicit treatment of the nexus in the industrial context is still not very well pronounced, and it is mainly manifested in the development of process integration methodologies for the simultaneous optimization of water use and energy efficiency in the design or refurbishment of process plants [20]. 
Even though energy, carbon and water related indicators are commonly calculated in industrial LCA studies, practical case studies discussing the interdependencies of these flows are rare, and mainly derive from the food industry [21,22] and the textile industry [23].

In the steelmaking industry, awareness of resource efficiency problems is high. In fact, iron and steelmaking is an energy intensive sector which currently accounts for about $18 \%$ of primary energy consumption and $11 \%$ of total electricity consumption of European industries [24].

As a consequence, steelmaking is also a carbon intensive sector, which accounts for $5 \%$ of total $\mathrm{CO} 2$ emission in the world [25]. The steelmaking industry is currently subjected to emission trading schemes (ETS) in several countries, particularly in the European Union (EU ETS), where a market of carbon emission allowances was introduced in 2005 to meet the international commitments under the Kyoto protocol [26].

Steelmaking processes also require large water flows (about $28 \mathrm{~m}^{3}$ per ton of steel) [27], mainly used for cooling purposes, and some studies are concerned with water footprint calculation for the sector [28]. A position paper published by the World Steel association in 2015 [27] expresses a nexus view of the sector, fostering a holistic approach which should consider additional energy requirements and all environmental aspects when introducing water management policies and evaluating discharge reduction projects.

Thus, awareness of nexus problem in the industry is high, but beside the mentioned position papers, no case studies on interdependences between water and energy consumption could be found in literature on steelmaking. While many studies deal with energy efficiency and carbon emission reduction projects in steelmaking (e.g. [29]-[33]), none of them seems to evaluate the implications of these projects for water consumption.

Apparently, it is generally assumed that energy recovery generates overall benefits also for other resources.

The objective of this paper is to verify this assumption for a test case, i.e. to assess the impact of selected energy recovery options, particularly for low grade waste heat recovery from cooling systems, for steelmaking plants located in Europe, in terms of energy, carbon and water impact. Taking a nexus view, the paper will analyse the implications of different economic conditions in European countries and the possible effect of carbon reduction policies on the feasibility of different technology options, and in turn on their impact on water and energy consumption.

There are two main technology pathways for steel production, i.e. either iron extraction from iron ore and refining through a reduction process based on blast furnaces and basic oxygen 
furnaces (BF-BOF) or recycling steel scrap through a melting process performed in an electric arc furnace (EAF). In this paper we will focus on the EAF route, which currently generates about $30 \%$ of global steel production [34], because recycling is expected to increase in the next few years and because this route is usually characterized by higher water consumption. In fact, because of the magnitude of involved materials and water flows, BF-BOF sites are usually located close to natural water sources (typically the sea) and cooling is performed through once-through cooling systems [27]. These systems, which take water from the sea, circulate it through the plant heat exchangers and return it to the local source, are characterized by high water withdrawals, but relatively low water consumption. Typical EAF plants, on the other hand, are relatively small systems located close to end markets of steel, usually in inland areas, which often use closed-loop or wet recirculating cooling systems. These systems reuse cooling water in a second cycle rather than immediately returning it back to the original water source.

Most commonly, wet recirculating systems use cooling towers to expose water to ambient air. Some of the water evaporates; the rest then sent back to heat exchangers for process cooling. These systems have much lower withdrawals that once-through systems, but tend to have appreciably higher water consumption [35].

To avoid excessive water consumption, closed circuit dry air-cooled systems are often used in EAF systems. In this case, the process medium itself or an intermediate coolant (typically water) is cooled down by conduction and convection through an air stream, created by fans, which flows past the tubes. Because the heat capacity of air is low and the coefficient of conduction and convection is low, large air flows are needed and a larger heat exchanging surface is required than with water cooling. Capital costs and energy consumption are hence higher than in wet cooling systems of similar performance, but water make-up requirements are negligible, even when is used as secondary coolant, because circuits are closed.

The motivating case study for this work, which will be examined in section 2, comes from an Italian EAF site, where dry cooling systems are currently used and options for recovering low grade waste heat from cooling systems are being evaluated to improve energy and carbon efficiency.

In order to estimate the carbon footprint, the water footprint and the primary energy factor of current and alternative technology options, methodologies and data reported in section 3 are used, including the development of a Monte Carlo model to account for the high variability of life-cycle parameters depending on different data sources. 
While the study starts from an Italian case, a general analysis is performed for Europe, though restricted to the EU-15 due to the lack of data for remaining countries. The economic feasibility of selected technology options for waste heat recovery will be evaluated under average conditions applied to industries in the EU-15 and their water-energy-GHG impacts will be assessed. Given the mentioned lack of indicators of water consumption for electricity generation for the EU-15 in literature, their estimates will also be firstly calculated in section 4, which will present the results of economic and water-energy-GHG analysis.

To evaluate the behaviour of steelmaking industries based on calculated performance indicators, we assume that the rationale of company choices is purely economic, i.e. that the technology options with the lowest expected life cycle costs are selected, including electricity and water costs, as well as carbon prices. In particular, the sensitivity of the economic performance to carbon prices will be examined in section 4 , where the potential water-energy nexus implications of carbon allowances for similar waste heat recovery projects in Europe will also be discussed.

\section{CASE STUDY DESCRIPTION AND TECHNOLOGY OPTIONS}

\subsection{Case study description}

The recovery of low grade waste heat from industries is considered as an enabler of energy efficiency and $\mathrm{CO} 2$ emission reduction, and recent literature is therefore rich in contributions reviewing recovery technologies for specific processes and industry sectors [36-38], or estimating waste heat potentials at regional, international and global levels [39-41].

The company of concern is a EAF steel mill operating on a 24/7 basis, employing about 600 people, with a yearly production of about 1,5 Mt of steel, subject to EU ETS obligations for the reduction of GHG emissions.

The waste heat recovery opportunity of concern derives from the first part of the off-gas cooling system of the EAF, the so called water cooling duct (WCD) which is represented in Figure 1. The structure of the off-gas cooling system is typical for EAF processes, and is described in detail in [42]. The off-gas enters the settling chamber, where larger particles are separated to reduce sediments in following sections, flows through the water cooling duct (WCD), which cools it to about $600^{\circ} \mathrm{C}$, and is further cooled to $200-300^{\circ} \mathrm{C}$ by a quenching tower (QT). The primary gas at $200-300^{\circ} \mathrm{C}$ is then blended with secondary gas at $50-70^{\circ} \mathrm{C}$ coming from the canopy hood situated over the furnace, so that the final mixture reaches a temperature which allows further de-dusting in a cyclonic separator and in the fabric filters of the baghouse collector. 
For the heat recovery system of concern, we have considered the opportunity of deriving a water flow from the cooling water circuit corresponding to a heat flow of about $1000 \mathrm{~kW}$. Such heat flow is however only which is only a fraction of the total heat flow available at the WCD. Hot water leaving the WCD currently enters a dry cooling device at temperature T11 and leaves it at temperature $\mathrm{T} 12,10^{\circ} \mathrm{C}$ below $\mathrm{T} 11$.

T12 is based on the average EU-15 external dry bulb temperature raised by an exchanger temperature difference falling in the range suggested by [43].

The process is intermittent, as the EAF operates as a batch melting process based on the so called tap-to-tap cycle, which includes furnace charging, melting, refining, de-slagging, tapping and furnace turn-around. The tap-to-tap time is about 40 minutes, which results in a typical pattern in flue gas temperatures thoroughly described in literature [32]. Variations in flue gas temperatures correspond to oscillations in cooling water temperature at heat recovery outlet (T1 in figure 1). Because a smoother temperature profile is needed for most recovery options, a hot water tank is interposed as storage system. Figure 2 shows temperature profiles of hot water leaving the tank (T2 in Figure 1) depending on storage size for the identified $1000 \mathrm{~kW}$ waste heat flow. Temperature oscillations within a range of $\pm 5{ }^{\circ} \mathrm{C}$, i.e. between 85 ${ }^{\circ} \mathrm{C}$ and $95^{\circ} \mathrm{C}$, were deemed acceptable, and a $100 \mathrm{~m}^{3}$ hot water storage system was selected.

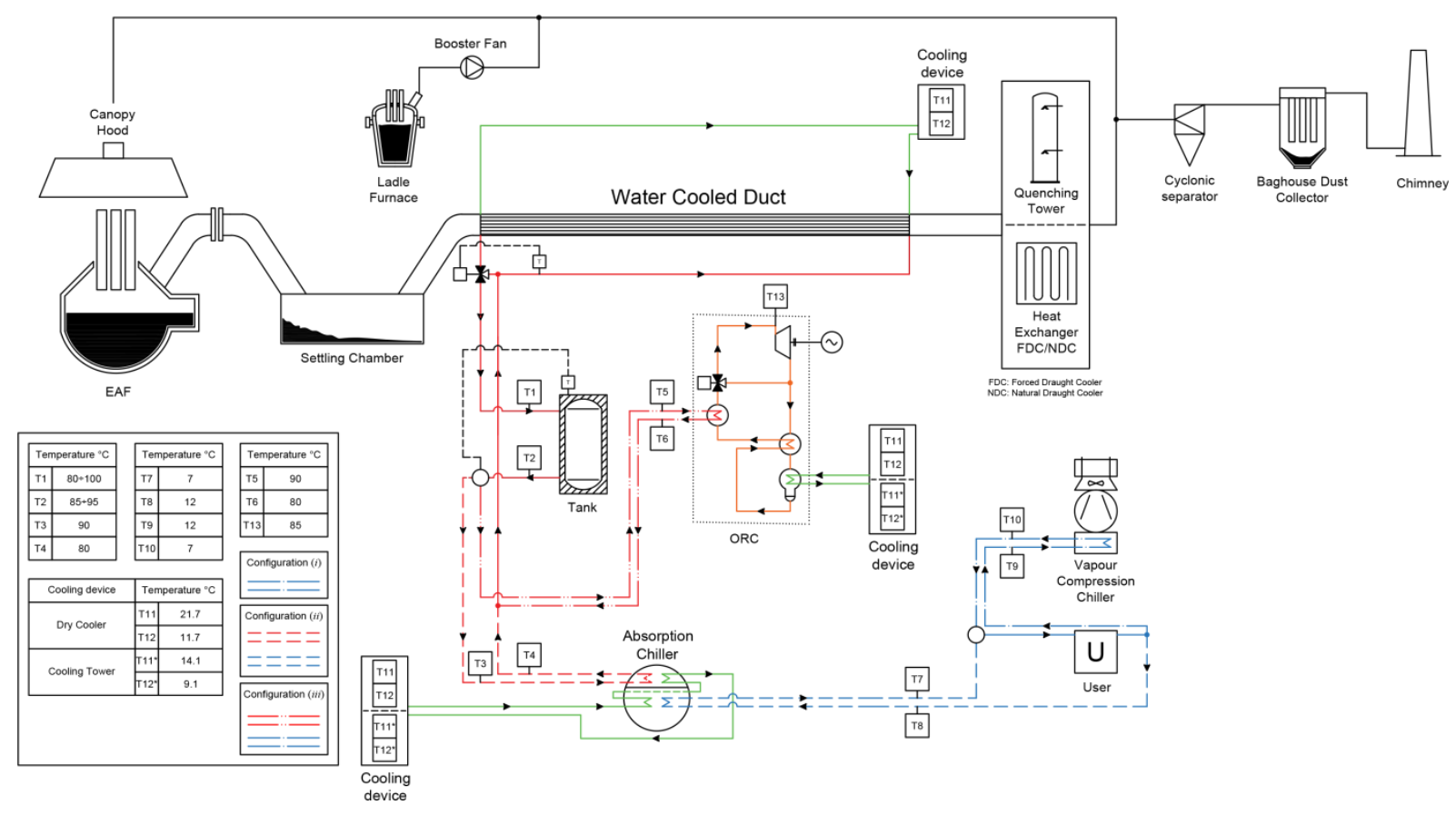

Figure 1 Process scheme and waste heat recovery options 


\subsection{Waste heat recovery options}

Literature on heat recovery for steelmaking processes [31] suggests direct use of heat, e.g. via district heating systems, as a first option. For such projects to be economically feasible, suitable heat sinks within an economically feasible distance should exist, which is not the case for the system of concern and for many similar sites in Europe.

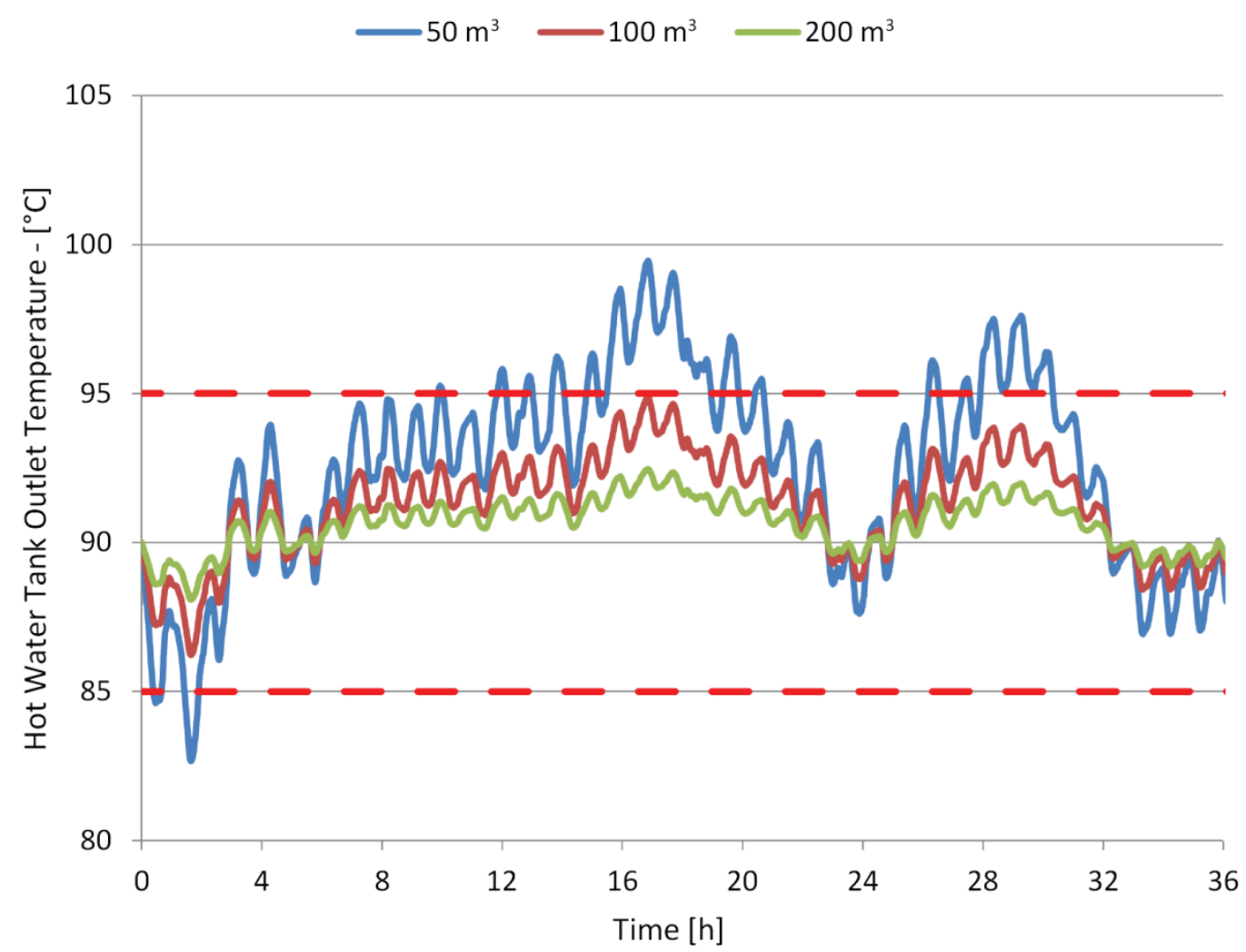

Figure 2 Temperature profiles of hot water at the tank outlet depending on tank size

Even direct use of heat within the steelmaking mill has not been considered in this case study, because low temperature internal heat demand is already met with other waste heat flows.

If the site has a suitable process or ambient cooling demand, requiring chilled water at about $10^{\circ} \mathrm{C}$, and waste heat at suitable temperature levels (typically above $70^{\circ} \mathrm{C}$ ), thermally driven cooling machines, particularly based on lithium bromide absorption cooling (see e.g. [44]) can also be considered as an active waste heat conversion technology.

At electric steelmaking sites, chilled water is required for air conditioning of electric transformer, generator and switch cabinets, mostly located within factory sheds. 
At the steel mill in question, chilled water at $7^{\circ} \mathrm{C}$ outlet temperature is currently obtained by several vapour compression chillers meeting an average cooling load of $500 \mathrm{~kW}$ with an average measured energy efficiency ratio $(\mathrm{EER})^{1}$ of 4 . The cooling load is represented by user $\mathrm{U}$ in Figure 1 and its existing circuit, entering user at $\mathrm{T} 9=7^{\circ} \mathrm{C}$ and exiting at $\mathrm{T} 10=12^{\circ} \mathrm{C}$, is represented with blue linepoint tract.

Every refrigeration cycle, both mechanical compression and absorption based, requires heat to be discarded to the environment to enable condensation of coolant fluid at the condenser. Refrigerators are thus usually coupled with heat dissipations systems, either dry or wet. While domestic and small scale systems are air-cooled, for large scale refrigerators used in industrial contexts the choice between dry cooling and wet cooling is determined by the expected economic performance.

For the case study in question, condensation of the refrigerant in the vapour compression units is currently performed exchanging heat to air, i.e. with dry cooling. Thus, the reference case, representing the current situation, is identified as configuration $(i)$ in Figure 1 and in the following. Configuration (i) includes the independent vapour compression cooling system represented with blue linepoint tract in Figure 1, and no heat recovery from the WCD. In Figure 3, which summarizes the analysed system configurations, boundaries and direct flows, it is shown that only electricity is consumed in configuration $(i)$, because water circuits are closed and dry cooling is used for WCD water cooling and for chiller.

When waste heat is recovered to drive absorption cooling machines, only single effect absorption chillers can be used, because hot water is available at an average temperature $\mathrm{T} 3=90^{\circ} \mathrm{C}$, associated with oscillations between $85^{\circ} \mathrm{C}$ and $95^{\circ} \mathrm{C}$ as detailed above. A reference EER of 0.7 is assumed for these machines, based on manufacturers' catalogues [45][46] and literature [44].

In this configuration, identified as (ii) in Figures 1 and 3, substitution of vapour compression units with single effect absorption chillers is associated with the centralization of heat dissipation systems, which makes it reasonable to consider cooling towers as an option for dissipating heat from refrigeration cycles.

Figure 3 shows that configuration (ii) requires direct electricity demand for auxiliaries and circuit pumps. If cooling towers are used, also a direct water consumption is required. In this case, water enters cooling towers at $\mathrm{T} 11^{*}$ and leaves them at $\mathrm{T} 12 * . \mathrm{T} 12 *$ and $\mathrm{T} 11^{*}$ are based

\footnotetext{
${ }^{1}$ In accordance with standard EN 14511, the characteristic parameter of a refrigerator is the energy efficiency ratio (EER), defined as ratio of the total cooling capacity to the effective power input of the unit, expressed in Watt/Watt
} 
on a cooling tower approach and range, respectively, falling in the intervals suggested by [43], starting from the average EU-15 outdoor wet bulb temperature.

Brückner et al. [47] report that, assuming an operation time of $2500 \mathrm{~h} / \mathrm{year}$, absorption cooling is of little interest for industrial consumers requiring high returns on their investments. However, cooling of internal electric cabinets within a process plant working on a 24/7 basis is a basic process requirement, likely to be interrupted only during protracted production stops or for maintenance. A yearly operation time of $7000 \mathrm{~h} /$ year can thus be reasonably assumed for these auxiliaries in steelmaking mills.

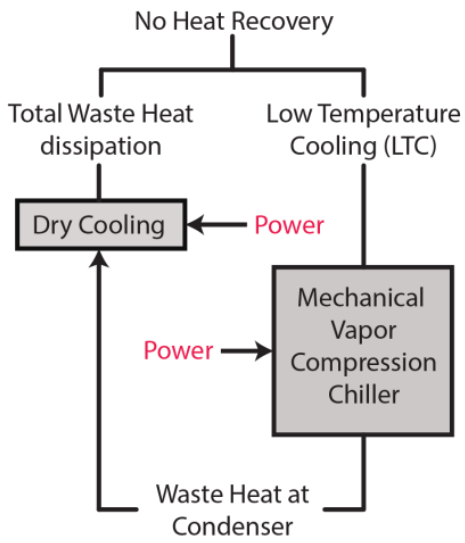

(i)

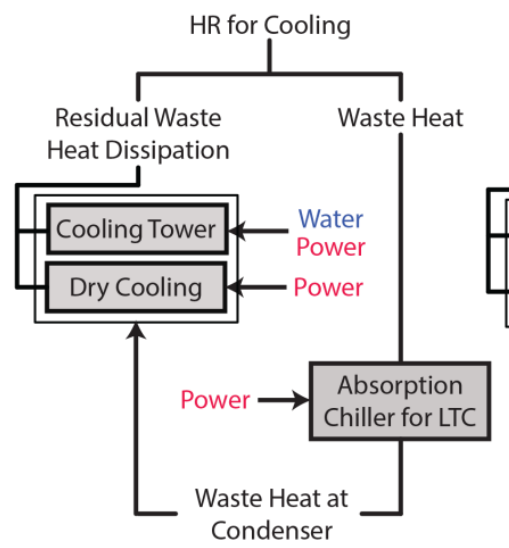

(ii)

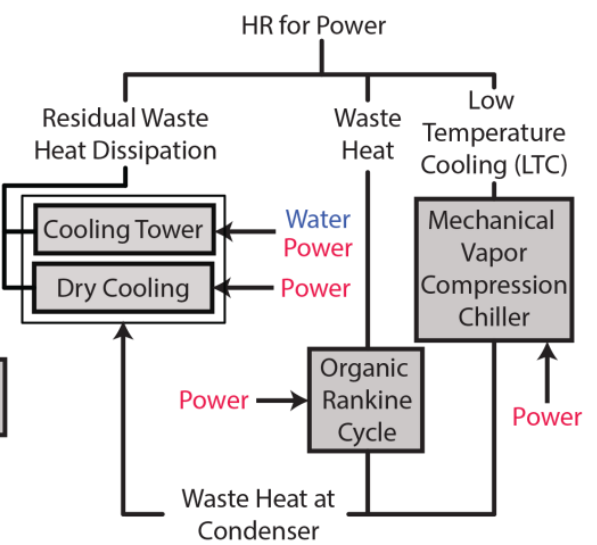

(iii)

Figure 3. Summary of electricity and power flows for the reference configuration (i) and the alternative recovery options (ii) and (iii)

If a direct use of waste heat is not feasible, power generation is considered as an energy conversion option to exploit waste heat. In particular, for low grade waste heat available from heat sources at temperature higher than $80^{\circ} \mathrm{C}$, including cooling water from EAF and heating furnaces, Organic Rankine Cycles (ORC) are identified by [31] as the most economically attractive conversion technology, also because of their commercial readiness [48]. Although the efficiency of ORCs at low temperature is necessarily low, "even technologies with low conversion efficiencies can be of interest if there is no other use for the excess heat" [31].

Heat recovery through an ORC is thus an option considered in this study, represented in orange and connected to line dot dot tracts in Figure 1 and identified as configuration (iii) in Figures 1 and 3. ORC is introduced as an alternative option to allow economic and technical comparison, as well as for the purposes of generalization to other process industries in Europe, as it is possible that industries with similar heat recovery opportunities do not have similar low temperature cooling demand.

To enable comparison, in configuration (iii) we assume that the same heat flow as in (ii) is recovered for power generation, i.e. about $700 \mathrm{~kW}$. Considering an average inlet temperature 
(T5 in Figure 1) of $90^{\circ} \mathrm{C}$ and an outlet temperature (T6) of $80^{\circ} \mathrm{C}$, a minimum temperature approach of $5^{\circ} \mathrm{C}$ between the heat source and the working fluid is assumed. At these conditions, the estimated efficiency of the ORC is about $9 \%$, which is in line with values reported by [37] and by [48] for heat source temperatures above $80^{\circ} \mathrm{C}$.

\section{METHODOLOGY AND MODEL BUILDING}

\subsection{Water, energy and carbon footprint evaluation}

Carbon footprint has been defined as "the quantity of GHGs expressed in terms of $\mathrm{CO}_{2}$ equivalent mass emitted into the atmosphere by an individual, organization, process, product or event from within a specified boundary" [49]. As observed by [49], in spite of numerous standards, there is lack of uniformity over the selection of direct and embodied emissions in literature, and defining system boundaries is thus a fundamental step in carbon footprint evaluation.

To evaluate water, energy and carbon footprints in this case study, the boundaries of the systems have been defined based on flows previously identified in Figure 3. In fact, these are the main relevant and differential flows for the examined configurations, because their level changes as a direct result of the decision between options (i), (ii) and (iii).

As e.g. in [50], the assumption in this study is that the technology switch from vapour compression units to absorption cooling systems is not associated with changes in direct carbon equivalent emissions from refrigerant leaks. Also, carbon equivalent emissions from organic fluid leakages in the ORC system have been neglected, since cycles at assumed temperature conditions and efficiency can be performed with low GWP fluids such as R152a [48]. Thus, only embodied emissions in purchased electricity have been incorporated in carbon footprint evaluation. Similarly, primary energy consumption associated with purchased electricity was calculated based on site-to-source energy conversion factors [51].

Water footprint is generally defined as the measure of "the volume of fresh water used to produce a product over the full supply chain, showing water consumption by source and polluted volumes by the type of pollution" [15]. In the present study, however, water footprint refers to a process, rather than to a product, and particularly to the configurations identified above. Since all these options concern auxiliary systems, none of them impacts on total steel production at the steelmaking mill in question. 
The present evaluation is also limited to blue water footprint, which measures the consumptive use of surface and ground water, rather than encompassing also grey water, i.e. measuring water pollution.

In this case, the freshwater footprint has been calculated as the sum of the direct blue freshwater consumption, evaluated with the system model described in subsection 3.2, and indirect blue freshwater consumption embodied in purchased electricity, evaluated as in [15], combining data from the literature on water consumption per $\mathrm{MWh}_{\mathrm{el}}$ for various energy sources with data on electricity production mix per country. As several sources and datasets are used, as illustrated in section 4, estimates are subject to significant uncertainty, which is treated with a Monte Carlo approach introduced in subsection 3.3.

\subsection{Energy and water flow balances for reference and heat recovery options}

Waste heat flows $Q_{r}$ to be dissipated for condensation in refrigeration cycles can be estimated according to equation 1 as a function of useful cooling effect $Q_{c}$.

$$
Q_{r}=\left(1+\frac{1}{E E R}\right) Q_{c}
$$

As absorption based refrigeration has lower EER than MVC based refrigeration, relevant waste heat flows are higher. In the case at hand, however, one should consider that waste heat comes from a cooling water circuit, which would anyway require a cooling system (a dry cooler, at the moment) to dissipate the waste heat flow $Q_{w}$ to cool water down to $80^{\circ} \mathrm{C}$ on average. Recovering a part of this flow to feed an absorption chiller implies a reduction of total dissipated heat, which compensates for the relative increase in the cooling load at the condenser of refrigeration cycles due to its lower EER. The total cooling load at dry-coolers without heat recovery (configuration $i$ in Figure 1) is thus given by equation 2:

$$
Q_{d}=Q_{w}+\left(1+\frac{1}{E E R_{c}}\right) Q_{c}
$$

whereas when heat is recovered for absorption cooling (configuration ii) the total load for the cooling system is given by:

$$
Q_{H R, a}=Q_{w}-\frac{Q_{c}}{E E R_{a}}+\left(1+\frac{1}{E E R_{a}}\right) Q_{c}=Q_{w}+Q_{c}
$$


To obtain an electric power output $P$ from the ORC in configuration (iii), the waste heat flow to be transferred from the process to the cycle evaporator equals $P / \eta$.

Thus, the cycle energy balance, and particularly the heat to be dissipated at the ORC condenser, implies that the total load for the cooling system in this configuration is:

$$
Q_{H R, p}=Q_{w}-\frac{P}{\eta}+(1-\eta) \cdot \frac{P}{\eta}+\left(1+\frac{1}{E E R_{c}}\right) Q_{c}
$$

Having assumed that in configuration (iii) the same heat flow as in (ii) is recovered for power generation, the electric power output can be expressed as $P=\frac{\eta \cdot Q c}{E E R_{a}}$. Thus, the total load to be dissipated in configuration (iii) is:

$$
Q_{H R, p}=Q_{w}-\frac{\eta \cdot Q c}{E E R_{a}}+\left(1+\frac{1}{E E R_{c}}\right) Q_{c}=Q_{H R, a}+Q_{c}\left(\frac{1}{E E R_{c}}-\frac{\eta}{E E R_{a}}\right)
$$

the heat load to be dissipated is larger in (iii) than in (ii). When evaluating energy and water consumption for alternative dissipation systems, for configuration (iii) it will be assumed that low temperature cooling systems are not modified and thus remain coupled with their current, dry cooling system. As a consequence, the heat load to be dissipated by the alternative cooling systems considered will equal:

$$
Q_{H R, i i i}=Q_{w}-\frac{P}{\eta}+(1-\eta) \cdot \frac{P}{\eta}=Q-P
$$

If wet cooling systems are used to dissipate residual heat, consumed water $W$ can be estimated as a function of evaporated water:

$$
W=k \frac{Q_{l}}{L}
$$

$L$ being the latent vaporization heat of water (here set at $2200 \mathrm{~kJ} / \mathrm{kg}$ ), $Q_{l}$ the thermal load in $\mathrm{kW}$ and resulting $W$ being expressed in $\mathrm{kg} / \mathrm{s}$.

Coefficient $k$ accounts for additional water losses due to bleed off and drift. Since the water is recycled and there is an opportunity for water constituents to be concentrated in the evaporative step, bleed off of high mineral water and makeup with freshwater of acceptable quality is required to keep solid concentration in water circuits below an acceptable threshold [35]. Losses due to drift are usually minimal, while the effect of bleed off is comparable with evaporation. Thus, $\mathrm{k}=2$ is a reasonable estimate. 
If dry cooling systems are used, the direct consumption of water is zero. However, an indirect consumption of water is associated with the electrical energy consumption of these systems. In this work, the electrical consumption of dry cooling systems was empirically estimated by interpolating drive power demand data provided by manufacturers (e.g. [52], [53]) as a linear function of cooling load:

$$
P_{D}=a+b Q_{l}
$$

Where $Q_{l}$ is the thermal load in $\mathrm{kW}, a=4 \mathrm{~kW}$ and $b=0.03 \mathrm{~kW}_{\mathrm{el}} / \mathrm{kW}$ and the resulting power consumption $P_{D}$ is expressed in $\mathrm{kW}$. Both for dry and wet cooling systems, power consumption for water pumping should also be added, which is estimated as:

$$
P_{W}=\frac{\Delta h \cdot Q_{l}}{\eta_{p} c_{p} \rho \cdot \Delta t}
$$

with $\Delta h$ being the circuit head loss in $\mathrm{Pa}$ (46 $\mathrm{kPa}$ for the system of concern), $\mathrm{c}_{\mathrm{p}}$ the constant pressure specific heat in $\mathrm{kJ} /(\mathrm{kg} \mathrm{K}), \Delta t$ the temperature difference, $\rho$ the water density and $\eta_{p}$ the pump electric efficiency.

\subsection{Monte Carlo model building}

Based on equations (1-9) an energy system model has been built for the configuration of concern, which was integrated with economic data enabling the calculation of life cycle costs for each configuration. Configuration $(i)$ is taken as reference, base case and both the dry cooling $(D C)$ and the cooling tower $(C T)$ variant for each heat recovery configuration (ii) and (iii) are evaluated under the assumptions clarified with equation 6.

The economic feasibility of each alternative has been assessed for average EU-15 economic data, using sources detailed in section 4 , to generalize the evaluation of the case study of concern to the European context.

Variability in data and consequent uncertainty in estimates are high, therefore the Monte Carlo approach is taken, which allows to synthesize the various sources of uncertainty of a problem and to account for all possible values that can be assumed by uncertain parameters, weighted by their probability of occurrence [54]. The Monte Carlo approach is widely used in 
energy and environmental analysis [55], and has recently been applied for regional waterenergy nexus evaluations by [56] and [57].

The modeling procedure through Monte Carlo simulation includes the following steps [55]:

1. Specification of uncertain model parameters.

2. Selection of a probability distribution describing the possible value range for each uncertain parameter.

3. Generation of the output variable from randomly selecting input values on the basis of the selected distribution for a large number of iterations.

In the present study, the technical parameters (i.e. conversion plant efficiency, EERs, cooling and power loads and parameters appearing in equations 1 to 9 ) are assumed to be known with certainty. Uncertainty is associated with economic parameters including:

- capital costs of installed equipment;

- annual operation time;

- water and electricity prices;

- interest rate;

- investment duration, which in this sector is usually significantly shorter than technical lifetime of plants due to economic obsolescence and payback constraints set by shareholders.

As in [58] this variation is representative of the unstable economic environment which is faced by investors making their medium term plans. Moreover, uncertainty is associated with emission, primary energy and blue water consumption factors for the purchased electricity, while the electricity generation mix of each country is assumed to be known with certainty, based on data derived from [59] and [60] for the year 2012.

Probability distribution types are defined by fitting available data or by expert judgement, in case of limited data availability. In particular, a set of appropriate distribution shapes has been defined subjectively, based on minimum and maximum values of the possible range of uncertain parameters retrieved in literature. For instance, continuous distributions extending to infinity, such as the lognormal or the gamma distribution, were excluded because economic and environmental parameter are realistically bounded. A preliminary analysis of extreme values reported in literature was also useful to exclude outliers, maintaining only values having the same order of magnitude. After that, distribution fitting is performed with the 
commercial software @ risk [61], which uses the Akaike Information Criteria to select the best distribution type and Maximum Likelihood Estimators to estimate distribution adjustable parameters [61].

Finally, the output is generated from repeated iterations. In particular, the average of the repeated iterations is an unbiased estimator of the expected value, and the law of large numbers assures that, for a large number of iterations, it converges to the expected value. Practically establishing the number of iterations required to assure convergence is a necessary step to obtain correct estimates, having an acceptable accuracy, i.e. within an acceptably tight confidence interval. The minimum number of iterations required to achieve a certain confidence interval can be calculated for each estimated parameter based on the central limit theorem as reported e.g. in [62]. In practice, as suggested by other authors adopting similar software packages for Monte Carlo analysis of investments in energy plants [63], the number of iterations was automatically established by @ risk to ensure convergence is achieved for all simulation outputs within $3 \%$ of the actual value of the mean at $95 \%$ confidence level [61].

\section{DATA COLLECTION}

A wide set of existing literature and data sources ([6],[15],[64]-[74]) are used to determine estimates for carbon emission, water consumption and energy consumption factors for each primary energy source; these estimates are combined with power generation mix data to obtain coherent carbon, water and energy indicators for each country. For all the data sources used ([6],[15],[64]-[74]) and for all indicators investigated, the estimates are based on a life cycle approach, i.e. all emissions or consumption from extraction to plant construction are considered. For this reason, emission factors are positive even for renewable sources which do not entail any combustion or direct use of water in their power generation cycle.

\subsection{Water, energy and GHG input data}

Distributions used for water-energy-carbon related data are reported in Tables 1-3.

It should be observed that water consumption values (Table 1) are the most uncertain, especially for hydropower, and even though a number of data sources exist, data fitting leads invariably to uniform distributions, i.e. every value within the usually wide range is equally probable. Table 1 reports the extremes of these ranges for the distributions.

For $\mathrm{CO}_{2}$ equivalent emissions, reported in Table 2, the best fit for data was obtained with triangular distributions when more data were available (e.g. for solid fuels, natural gas, solar 
energy, hydropower and wind energy), and it was also possible to develop subjective triangular distributions for remaining energy sources. For triangular distributions, minimum, maximum and most likely values are reported in all tables.

For primary energy factors, uniform distributions, whose range extremes are reported in Figure 3, were usually the best fit and have been also subjectively applied to solar energy, for which a single data source [69] was available.

Table 1. Consumed water per $\mathrm{MWh}_{\mathrm{e}}$ generated

\begin{tabular}{ccccc}
\hline Primary source & Distribution type & \multicolumn{2}{c}{$\begin{array}{c}\text { Characteristic Values } \\
\text { 1/MWhe }\end{array}$} & Data sources \\
& & min & $\max$ & \\
\hline Nuclear Energy & Uniform & 1677 & 2900 & {$[15,64,65,66,67,68$,} \\
& & & & $69]$ \\
Solid Fuels & Uniform & 1336 & 2600 & {$[64,65,66,67,68,69]$} \\
Natural Gas & Uniform & 687 & 1400 & {$[64,65,66,67,68,69]$} \\
Crude Oil & Uniform & 971 & 1697 & {$[65,67,69]$} \\
Solar Energy & Uniform & 7 & 4700 & {$[64,65,66,67,68]$} \\
Biomass \& Waste & Uniform & 1145 & 1853 & {$[67,68,69]$} \\
Geothermal Energy & Uniform & 5824 & 9033 & {$[67,68]$} \\
Hydropower & Uniform & 5394 & 68137 & {$[67,68,69]$} \\
Wind Energy & Uniform & 0 & 4 & {$[15,64,65,67,68]$} \\
\hline
\end{tabular}

Table 2. Carbon dioxide emitted per $\mathrm{GWh}_{\mathrm{e}}$ generated

\begin{tabular}{lccccc}
\hline Primary source & Distribution type & \multicolumn{3}{c}{$\begin{array}{c}\text { Characteristic Values } \\
\mathrm{tCO}_{2} / \mathrm{GWh}_{\mathrm{e}}\end{array}$} \\
& & Data sources \\
& & Min & $\mathrm{ML}$ & $\max$ & \\
\hline Nuclear Energy & Triangular & 16.0 & 23.2 & 30.0 & {$[69,70,71]$} \\
Solid Fuels & Triangular & 905.7 & 1,001 & 987.6 & {$[69,70,71,72]$} \\
Natural Gas & Triangular & 353.6 & 481.4 & 563.2 & {$[69,70,71,72]$} \\
Crude Oil & Triangular & 677.7 & 742.1 & 875.0 & {$[69,70,72]$} \\
Solar Energy & Triangular & 35.0 & 49.7 & 130.0 & {$[69,70,71,72]$} \\
Biomass \& Waste & Triangular & 18.0 & 34.5 & 51.0 & {$[69,71]$}
\end{tabular}




\begin{tabular}{lccccc} 
Geothermal Energy & Triangular & 15.0 & 45.0 & 104.0 & {$[69,70,71]$} \\
Hydropower & Triangular & 4.0 & 17.6 & 40.0 & {$[69,70,71,72]$} \\
Wind Energy & Triangular & 7.0 & 17.0 & 29.5 & {$[69,70,71,72]$} \\
\hline
\end{tabular}

$* \overline{\mathrm{ML}}=$ most likely

Table 3. Consumed Primary Energy per $\mathrm{kWh}_{\mathrm{e}}$ generated

\begin{tabular}{|c|c|c|c|c|c|}
\hline \multirow[t]{2}{*}{ Primary source } & \multirow[t]{2}{*}{ Distribution type } & \multicolumn{3}{|c|}{$\begin{array}{c}\text { Characteristic Values } \\
\mathrm{kWh}_{\mathrm{p}} / \mathrm{kWh}_{\mathrm{el}}\end{array}$} & \multirow[t]{2}{*}{$\overline{\text { Data sources }}$} \\
\hline & & $\min$ & $\max$ & $\overline{M L}$ & \\
\hline Nuclear Energy & Uniform & 3.07 & 3.50 & & {$[69,73,74]$} \\
\hline Solid Fuels & Uniform & 2.98 & 3.26 & & {$[69,74]$} \\
\hline Natural Gas & Uniform & 2.02 & 2.63 & & {$[69,74]$} \\
\hline Crude Oil & Uniform & 2.76 & 3.40 & & {$[69,74]$} \\
\hline Solar Energy & Uniform & 0.50 & 1.00 & & [69] \\
\hline Biomass \& Waste & Uniform & 0.20 & 4.53 & & {$[69,74]$} \\
\hline Geothermal Energy & Triangular & 0.40 & 6.16 & 4.24 & {$[69,73,74]$} \\
\hline Hydropower & Uniform & 0.06 & 1.15 & & {$[69,74]$} \\
\hline Wind Energy & Uniform & 0.03 & 1.00 & & {$[69,74]$} \\
\hline
\end{tabular}

\subsection{Economic input data}

Investment cost distributions, which are the main sources of uncertainty for economic feasibility assessment, are based on literature [31] and manufacturers' catalogues and communications ([45][46][52][53][75]) and are reported in table 4 in the form of size dependent cost functions, based on power and linear function shapes discussed e.g. in [76]. ORC is the most expensive technology [77], especially in the small capacity range associated with this application. Absorption chillers have an high proportion of size independent capital costs, which makes it advisable to avoid redundancies and load partitioning in order to minimize the number of units.

To assess the economic performance of generic plants, as in [58] triangular distributions are also used to estimate interest rates, investment duration and annual operation time. The expected values of these parameters, calculated under current conditions for the steelmaking sector, 
correspond to an interest rate of $7.3 \%$, an investment duration of 7.3 years and about 6100 operation hours per year. The impact of different market conditions in various EU countries is analysed by considering average prices of electricity and freshwater for industrial customers in each country.

Such values are particularly difficult to source. For electricity, the Eurostat database [78] is used and uniform probability distributions were applied to values obtained for the years (2012-2014). For freshwater, the last comparative study on industrial prices in Europe dates back to the year 2003 [79] and, as for industry, reports data for seven countries only.

Table 4. Investment cost distributions

\begin{tabular}{|c|c|c|c|c|c|}
\hline \multirow[t]{2}{*}{ Technology } & \multirow[t]{2}{*}{$\begin{array}{l}\text { Cost function structure } \\
\qquad(Y \text { in } €)\end{array}$} & \multirow[t]{2}{*}{ Parameter } & \multicolumn{3}{|c|}{$\begin{array}{c}\text { Characteristic Values of } \\
\text { parameter triangular } \\
\text { distribution }\end{array}$} \\
\hline & & & Min & ML & $\max$ \\
\hline Heat storage & $Y=\alpha$ & $\alpha$ & 15000 & 20000 & 30000 \\
\hline \multirow{2}{*}{ MVC chiller } & & $\alpha$ & 15000 & 20000 & 35000 \\
\hline & $\mathrm{Y}=\alpha+\beta \mathrm{Q}$ ( $\mathrm{Q}$ cooling power in $\mathrm{kW}$ ) & $\beta$ & 90 & 112 & 150 \\
\hline Absorption & & $\alpha$ & 86000 & 95000 & 110000 \\
\hline chiller & $\mathrm{Y}=\alpha+\beta \mathrm{Q}(\mathrm{Q}$ cooling power in $\mathrm{kW})$ & $\beta$ & 90 & 94 & 100 \\
\hline Dry cooling & $\mathrm{Y}=\mathrm{C}_{0}\left(\frac{Q_{d}}{Q_{0}}\right)^{m}\left(\mathrm{Q}_{\mathrm{d}}\right.$ dissipation & $\mathrm{C}_{0}$ & 6000 & 8000 & 12000 \\
\hline system & capacity in kW. $\mathrm{Q}_{0}=200 \mathrm{~kW}$ ) & $\mathrm{m}$ & 0.55 & 0.7 & 0.75 \\
\hline Wet cooling & $\mathrm{Y}=\mathrm{C}_{0}\left(\frac{Q_{d}}{Q_{0}}\right)^{m}$ (Qd dissipation & $\mathrm{C}_{0}$ & 48000 & 60000 & 110000 \\
\hline system & capacity in $\mathrm{kW} . \mathrm{Q}_{0}=8000 \mathrm{~kW}$ ) & $\mathrm{m}$ & 0.55 & 0.7 & 0.75 \\
\hline Organic Rankine & $\mathrm{Y}=\mathrm{C}_{0}\left(\frac{P}{P_{0}}\right)^{m}$ (P nominal power in & $\mathrm{C}_{0}$ & 150000 & 300000 & 400000 \\
\hline Cycle & $\left.\mathrm{kW}, \mathrm{P}_{0}=100 \mathrm{~kW}\right)$ & $\mathrm{m}$ & 0.7 & 0.8 & 0.9 \\
\hline
\end{tabular}

More abundant and recent literature concerns prices for households [80][81]. Our approach is thus to extrapolate the ratio between industrial and residential consumer prices from [79], obtaining an expected value of $77.5 \%$, and to apply it to household price distributions obtained from [80], integrated with other datasources as shown in Table 5. In particular, for 
Greece [64] and Luxembourg [65] direct data on recent industrial tariffs could be found. For all countries, uniform price distributions were assumed and their expected values are reported in Table 5.

A statistical correlation test has been performed for values reported in Table 5, finding that correlation is not statistically significant. For this reason, it has not been incorporated in the Monte Carlo model.

Table 5. Expected values of electricity and freshwater prices for industrial consumers

\begin{tabular}{lccc}
\hline Country & $\begin{array}{c}\text { Electricity Price* } \\
\text { EUR/kWhe }\end{array}$ & $\begin{array}{c}\text { Industrial Water } \\
\text { Price** } \\
\text { EUR/m }\end{array}$ & $\begin{array}{c}\text { Sources for } \\
\text { water prices }\end{array}$ \\
\hline Austria (Österreich) & 0.109 & 1.523 & {$[80]$} \\
Belgium & 0.110 & 2.329 & {$[80]$} \\
Denmark & 0.094 & 3.813 & {$[80]$} \\
Germany & 0.141 & 2.024 & {$[80][81][82]$} \\
Ireland & 0.136 & 1.113 & {$[83]$} \\
Greece & 0.126 & 0.886 & {$[84]$} \\
Spain & 0.119 & 1.199 & {$[80]$} \\
France & 0.085 & 1.726 & {$[80]$} \\
Italy & 0.175 & 0.771 & {$[80]$} \\
Luxemburg & 0.100 & 2.255 & {$[85]$} \\
Netherlands & 0.093 & 1.723 & {$[80]$} \\
Portugal & 0.117 & 1.381 & {$[80]$} \\
Finland & 0.074 & 1.754 & {$[80]$} \\
Sweden & 0.073 & 1.791 & {$[80]$} \\
United Kingdom & 0.127 & 1.743 & {$[80]$}
\end{tabular}

*Elaboration on Eurostat values [78]**For sources in dollars, the historical (2013) exchange rate of $1 \mathrm{USD}=0.77 €$ was used

\section{RESULTS AND DISCUSSION}

5.1 Calculation of water-energy-GHG nexus indicators for electricity generation in the EU-15 
As a first step, the model developed is used to estimate footprint indicators for electricity production in the EU-15 countries based on the energy mix as of year 2012 ([59][60]).

The expected values for their distributions are summarized in table 6 .

To validate the results, data on $\mathrm{CO}_{2}$ equivalent emissions reported by the European Environment Agency are derived from [86]. Differences between indicators reported in [86], and expected values calculated for the countries in question given by the model lead to a mean absolute percentage error (MAPE) equal to $17.4 \%$ and a mean percentage error (MPE) equal to $-7.0 \%$. Hence, the model estimates tend to be lower than values reported in [86]. This may depend on the fact that our estimates are based on the energy mix of year 2012, while data available from [86] refer to the year 2009.

Similarly, a reference for validating primary energy consumption data can be found in [73], which contains primary energy factors for a subset of the EU-15 (i.e. data for Austria, Belgium, Luxembourg and the UK are not available). Validation is approximate, in that most data in [73] are only graphically represented. Ordering countries by decreasing values of primary energy consumption per GWh leads to approximately the same country ranking represented in [73], with the notable exception of the Netherlands and Finland, who ranked, respectively between Italy and Sweden and at the lower end of the range, between Denmark and Portugal, according to [73]. Those countries are both characterized by significantly higher model based estimates of expected primary energy factors than those reported in [73]; for the Netherlands, also $2009 \mathrm{CO}_{2}$ eq emission factors according to [86] were significantly (22\%) lower than model estimates for 2012, while the opposite holds true for Finland, which has very low carbon emissions. A deeper analysis of model data reveals that Finland has the highest share of biomass and waste used for power generation in the EU-15, and that the model primary emission factors for biomass and waste are particularly high. This is especially due to values derived from [74], as a result of the high variability in biomass and waste composition, conversion technologies and relevant impact. A wider set of data, especially from a European context, would improve the model accuracy in evaluating the impact of bioenergy for the countries of concern.

With the exception of the Netherlands, primary energy consumption indicators calculated with the model for 2012 are generally lower than values reported in [73] for the year 2009 . The trend for efficiency increase highlighted by the authors of [73] is thus confirmed.

Due to the scarcity of industry and power generation oriented studies for Europe, only the continental data reported by [15] may aid to validate the simulated water consumption for electricity generation. They report a European average water consumptive footprint of 3240 
$\mathrm{m}^{3} / \mathrm{TJ}$, i.e. about $11660 \mathrm{l} / \mathrm{MWh}$. This value is considerably higher than our estimates, probably due to their significantly higher upper bounds of the consumptive water footprint for several energy sources, especially for bioenergy. A subsequent validation of these bottom up models with hybrid approaches based on input output models [12] could be the subject of future research, but is out of the scope of this study, which presents a first estimate of the freshwater consumption indicator for power generation in the European countries of concern.

Table 6. Expected values of carbon, water and primary energy indicators for electricity production

\begin{tabular}{lccc}
\hline Country & Simulated $\mathrm{CO}_{2 \mathrm{eq}}$ & $\begin{array}{c}\text { Simulated } \mathrm{H}_{2} \mathrm{O} \\
\text { consumption } \\
\text { t/MWhe }\end{array}$ & $\begin{array}{c}\text { Simulated } \\
\text { Primary Energy } \\
\text { TOE/GWhe }\end{array}$ \\
\hline Austria (Österreich) & 0.18 & 24972 & 110 \\
Belgium & 0.22 & 1800 & 240 \\
Denmark & 0.42 & 894 & 175 \\
Germany & 0.52 & 2575 & 224 \\
Ireland & 0.49 & 2152 & 189 \\
Greece & 0.66 & 3879 & 216 \\
Spain & 0.34 & 3767 & 191 \\
France & 0.08 & 5765 & 246 \\
Italy & 0.43 & 6488 & 180 \\
Luxembourg & 0.29 & 12366 & 144 \\
Netherlands & 0.53 & 1273 & 217 \\
Portugal & 0.42 & 5568 & 170 \\
Finland & 0.12 & 3839 & 244 \\
Sweden & 0.03 & 18786 & 157 \\
United Kingdom & 0.53 & 1942 & 234 \\
\hline & & & \\
\hline
\end{tabular}

Since model estimates for the three nexus indicators are based on the same dataset, some significant statistic correlation can be expected. Testing model results, a significant negative correlation $(r=-0.55)$ is found between water consumption and $\mathrm{CO}_{2}$ equivalent emissions and between water consumption and primary energy consumption $(r=-0.76)$. Hence, countries with 
higher carbon and primary energy indicators usually have significantly lower water consumption indicators, and vice versa. This is mainly due to the role of hydropower in energy systems, which is associated with low life cycle carbon equivalent emission factors (Table 2) and primary energy consumption (Table 3), but has the highest freshwater consumption footprints (Table 1). The result is in line with similar findings recently reported in literature [87].

The statistical correlation between $\mathrm{CO}_{2}$ equivalent emissions and primary energy consumption is not significant $(r=0.153)$. This result may appear counterintuitive, but it is justified by the effect of nuclear energy, which has minimum carbon impact but high primary energy consumption factors.

\subsection{Economic feasibility of the project at average EU-15 conditions}

The economic feasibility of the project has been evaluated first in absence of carbon related obligations or incentives, i.e. at null carbon price, at average EU-15 conditions as for water and electricity price. The investment analysis is performed on a differential analysis basis, by considering the differences between the required investment and resulting cash flows of proposed heat recovery and energy conversion alternatives and the reference base case with full dissipation through dry cooling. The investment indicators considered are equivalent annual costs, presented in Figure 4, and simple payback times, presented in Figure 5. In this case, the interest rate is fixed at $7 \%$ and investment duration at 10 years, while the sensitivity of project profitability to annual operation hours is tested by varying this parameter between $2500 \mathrm{~h} /$ year and $7000 \mathrm{~h} /$ year.

Box-whiskers diagrams highlight that at $7000 \mathrm{~h} /$ year median equivalent costs of all heat recovery projects are lower than base case medians, and simple payback time medians are lower than investment duration. Absorption cooling (configuration ii) alternatives, however, pay off in about one year, with minimum variance in case dry cooling systems are used. The payback of ORC projects (configuration iii) is much longer and has the highest level of uncertainty. With 2500 operation hours per year, power generation projects are not feasible without incentives or carbon prices, while median costs of absorption cooling systems remain below base case costs both for DC and CT alternatives. 


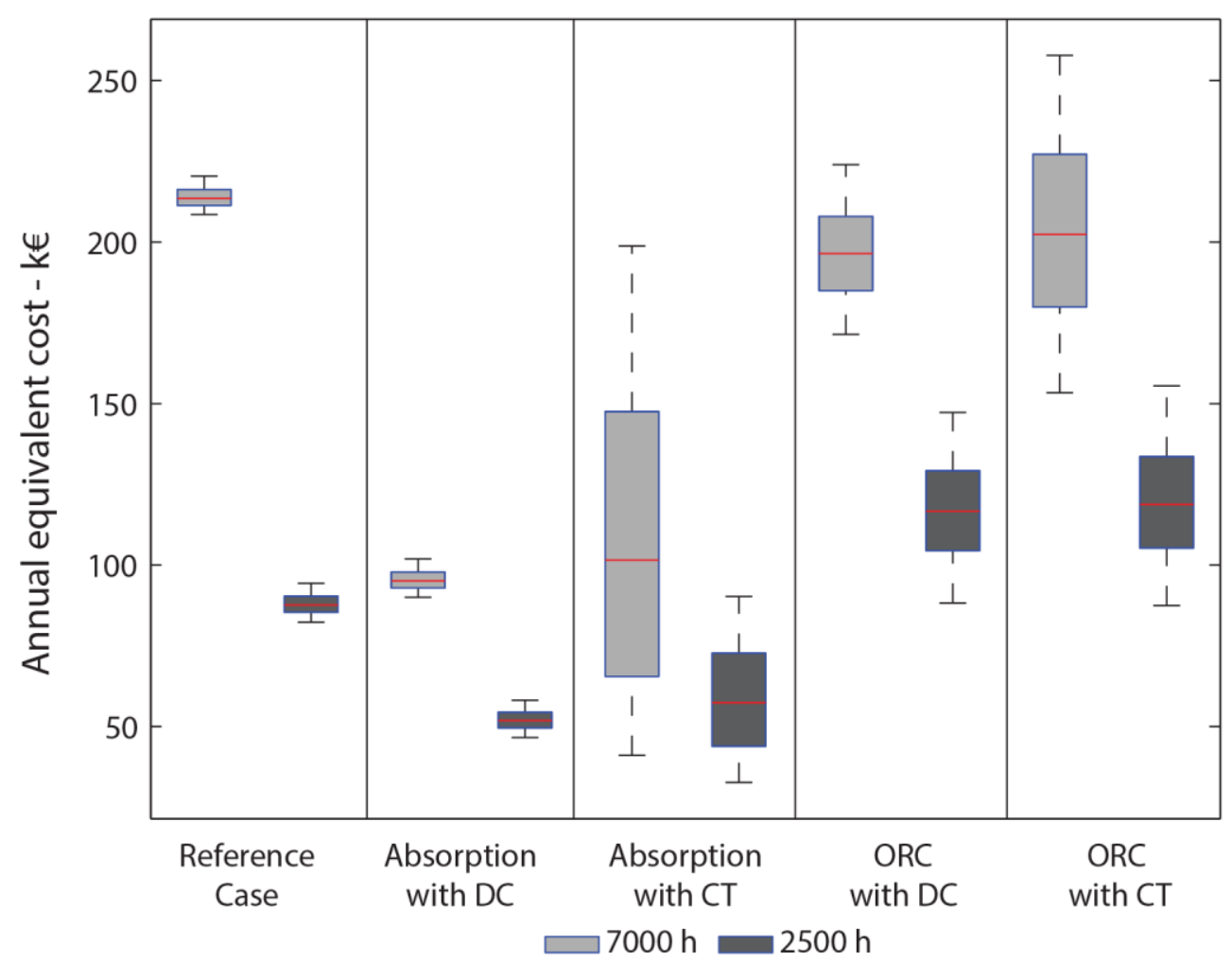

Figure 4. Equivalent annual costs of systems at average EU-15 conditions.

At the conditions considered, median payback times are acceptable for all absorption cooling variants also at $2500 \mathrm{~h} /$ year operation. However, solutions with CT have higher uncertainty, with the widest spans between maximum and minimum values and quartiles especially if the operation time increases.

For all heat recovery options, as we are considering an average distribution of power and water prices over the EU-15, the introduction of wet cooling systems as a complement to heat recovery leads to lower profitability and higher uncertainty, because of considerable variations in industrial water prices among EU-15 countries. In general, we would expect that without carbon incentives projects including dry cooling would be preferred. Looking at national outcomes however, results would be different, especially for Italy and other countries, as discussed in the following sections, where the nexus implications are also examined. 


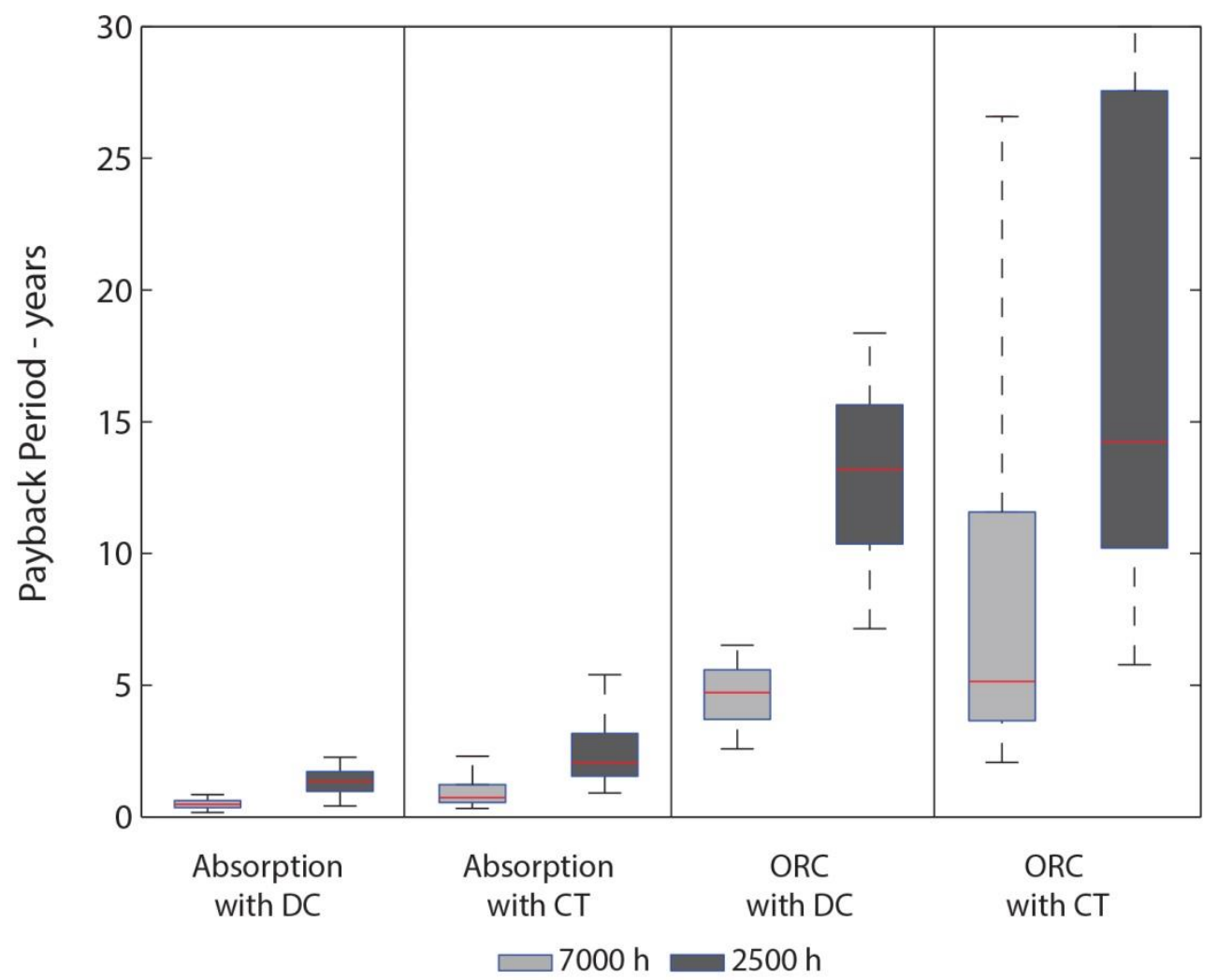

Figure 5. Pay back times at average EU-15 conditions.

\subsection{Nexus impact of carbon reduction policies in different EU-15 countries}

Policies aimed at carbon emission reduction have been debated in Europe since the early Nineties, and a variety of instruments have been proposed, including voluntary agreements, unilateral programs and multilateral programs [88], until the emission trading scheme for carbonintensive companies was launched in 2005. Research confirms that allowance prices are now integrated into several aspects of corporate decision making, although technological changes induced by the EU ETS are moderate, in that the industry prefers small scale projects with short term horizons rather than to large scale projects with higher returns, but also higher risks [89]. A sensitivity analysis was performed by varying carbon prices between zero (corresponding to the situation of firms not subject to the EU ETS or other unilateral carbon taxes) and $120 € / \mathrm{t}$ of $\mathrm{CO} 2$ equivalent emissions. The current market value of ETS allowances is around $8 € / \mathrm{t}$. While an increase to $20 € / \mathrm{t}$ is expected in the next years, the upper boundary of the proposed range may seem extremely high. However, renewable energy and other forms of investment in energy efficiency are subsidized with other instruments in some countries (e.g. white certificates or renewable energy feed in tariffs in Italy) whose cost, related to carbon equivalent reduction, is comparable with these ranges. 
Assuming that companies invariably choose the technology with the lowest annual equivalent costs, including costs from carbon allowances, the aim of this sensitivity analysis is to determine what carbon prices may induce:

- a technology switch from configuration (i) to configurations (ii) or (iii), respectively;

- a switch from one cooling system technology for residual heat dissipation to another.

Dry cooling is more energy intensive, and thus more carbon intensive, than wet cooling, which requires high water supplies, with corresponding costs. Hence, we test whether and where higher carbon prices may lead to a technology switch from energy intensive dry cooling to water intensive wet cooling.

For each analysis, the impact of technology switches on the expected values of water consumption, $\mathrm{CO}_{2}$ equivalent emissions and primary energy consumption of the project is displayed, in Figures 6-8 for configuration (ii), i.e. absorption cooling, and in Figures 9-11 for configuration (iii), i.e. ORC for power generation, respectively.

\subsubsection{Absorption cooling}

Based on the model results, the heat recovery project for absorption cooling would be feasible in every country, even at the lowest electricity prices, mainly thanks to the long operation time associated with the case study of concern.

In Figures 6-8, the resource efficiency indicators of the projects are plotted at zero carbon price and compared with the indicators for the base case $(i)$, represented as white bars. Water footprints are represented in Figure 6, $\mathrm{CO} 2 \mathrm{eq}$ emissions in Figure 7 and primary energy consumption in Figure 8.

Figures 6-8 also highlight the cooling system type selected at zero carbon price, which in all cases remains unchanged also at the current market price of about $8 € / \mathrm{tCO}_{2} \mathrm{eq}$. For most countries, the situation remains unchanged even with growing carbon prices, but in four countries, namely the United Kingdom, Germany, Austria and the Netherlands, marked with black arrows in figures 7 and 8, a switch from dry cooling to wet cooling systems for heat dissipation happens at the threshold values reported above the bars, i.e. at $20 € / t$ for the UK, 50 $€ / t$ for Germany and $80 € / t$ for Austria and the Netherlands.

Wet cooling systems would be selected even at zero or current carbon costs in Italy, Portugal, Spain, Greece and Ireland. According to our estimates, these countries have the lowest water prices, with expected tariffs ranging from less than $90 €$ cents $/ \mathrm{m}^{3}$ in Greece to almost 140 $€$ cents $/ \mathrm{m}^{3}$ in Portugal. With the exception of Ireland, these are Mediterranean countries, exposed to the highest risk of water scarcity. As shown in Figure 6, for configuration (ii) wet cooling 
entails a total water consumption of about $33000 \mathrm{~m}^{3} / y e a r$, including the generally small indirect water consumption, which is a function of the electricity demand for auxiliaries and ranges from approximately $40 \mathrm{~m}^{3} /$ year in the Netherlands to almost $770 \mathrm{~m}^{3} /$ year in Austria.

Independent of carbon price, dry cooling is the technology option chosen in Belgium, Denmark, France, Luxembourg, Finland and Sweden. Belgium, Denmark and Luxembourg have the highest water prices in Europe, whereas in France, Finland and Sweden water prices are intermediate, but industrial electricity prices and $\mathrm{CO}_{2}$ equivalent emissions for electricity generation are the lowest in Europe.

When dry cooling is chosen, the configuration (ii) of the heat recovery project invariably leads to an improvement of water footprint indicators, more evident in the countries with the highest shares of hydropower in their national energy mix.

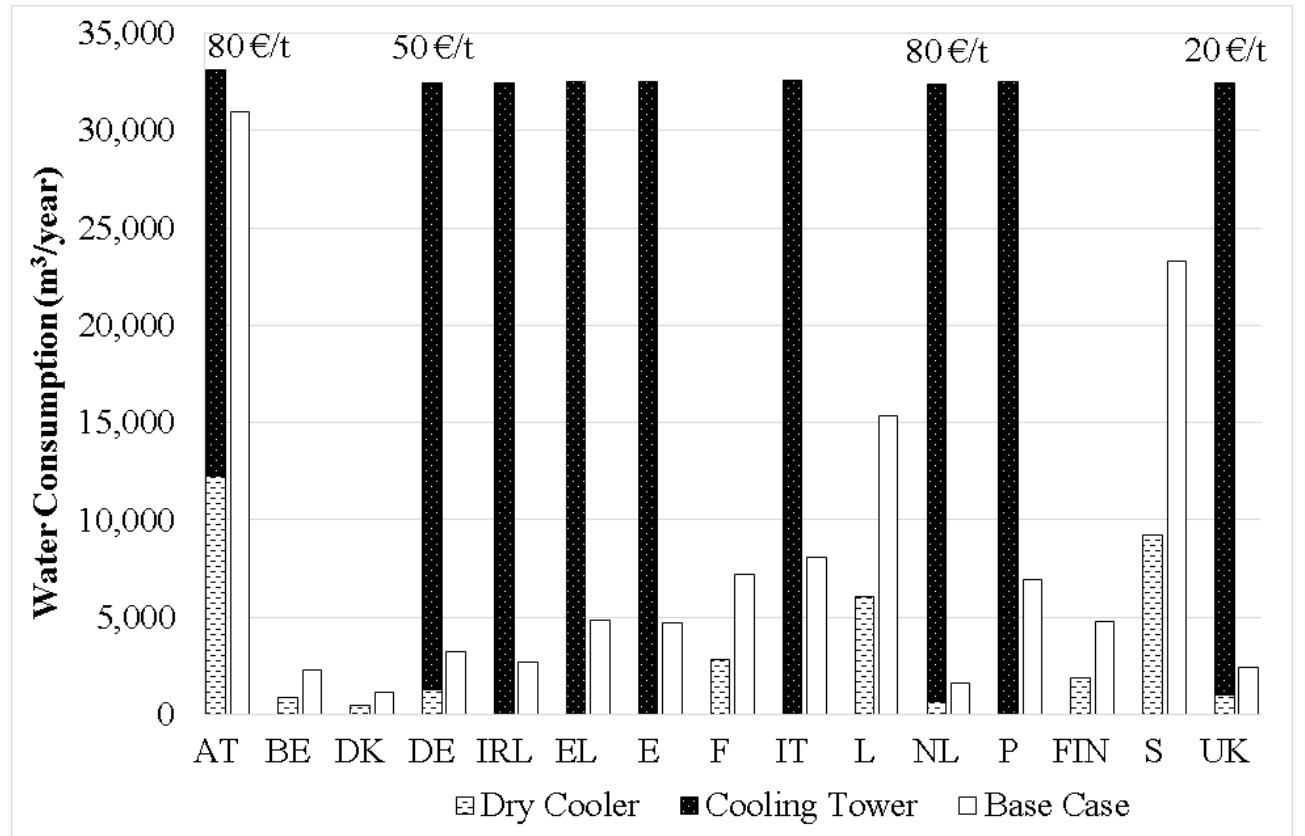

Figure 6. Water consumption for absorption cooling project in EU-15 at zero and current carbon price and at carbon prices determining cooling systems switch (labels above the bars).

Compared with the wet cooling option, the additional power demand for dry cooling is about 450 MWh/year, which implies additional carbon emissions and primary energy consumption of variable size, depending on country energy mix. Where dry cooling is preferred for the project, total $\mathrm{CO}_{2}$ equivalent emissions range between $16 \mathrm{t} /$ year in Sweden and $203 \mathrm{t} /$ year in Denmark (Figure 7) and primary energy consumption ranges from 54 TOE/year in Austria to 120 TOE/year in France and Finland (Figure 8). 
Net benefits deriving from the heat recovery project in configuration (ii) are always high even with dry cooling, both as to $\mathrm{CO}_{2}$ emissions and as to primary energy consumption. When wet cooling is preferred, however, the increase in direct water consumption is never offset by the decrease in indirect water consumption associated with lower electricity consumption, even in the countries with the highest water footprints for electricity production, such as Austria. This fact mainly depends on the high residual waste heat flows to be dissipated by the condenser of absorption cooling plants, having an unfavourable ratio to the net electricity consumption avoided through waste heat recovery.

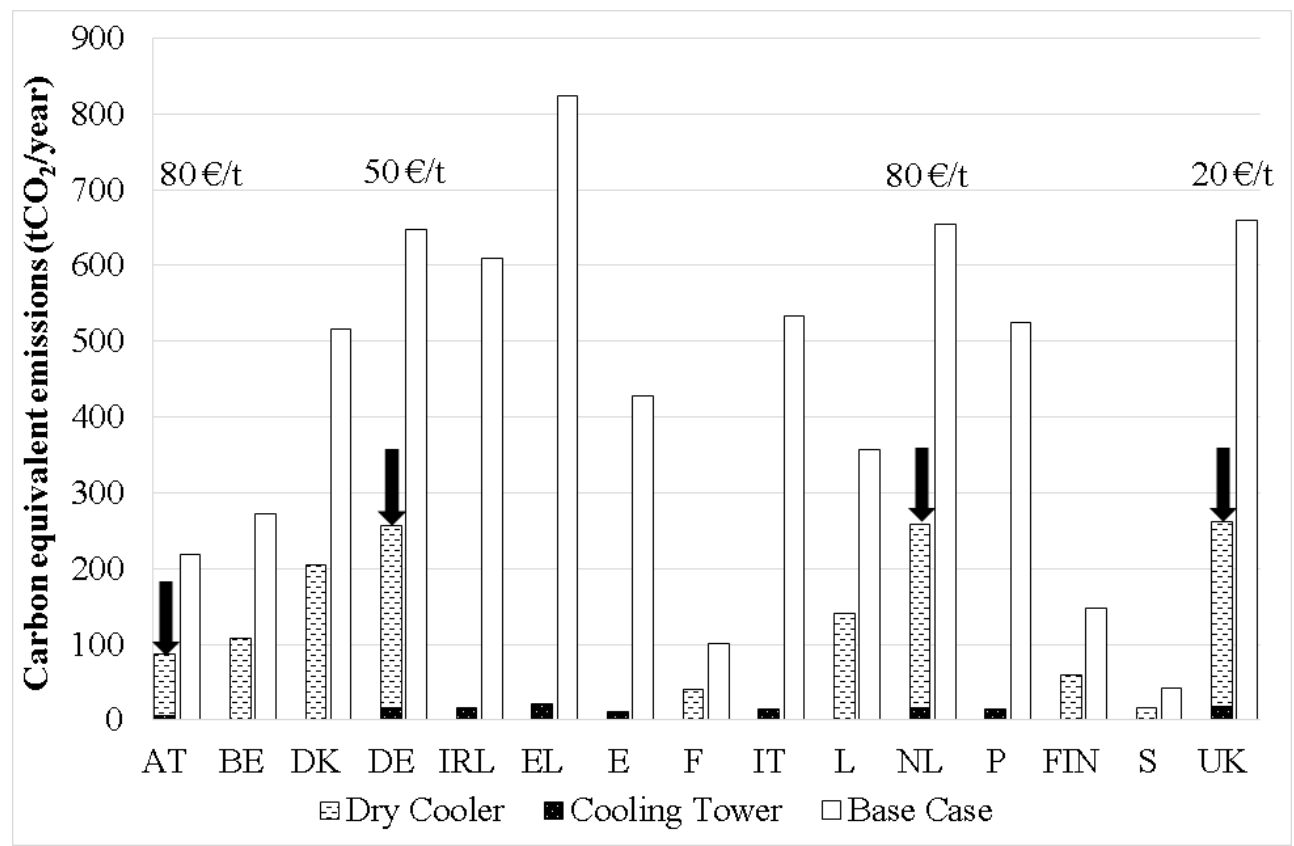

Figure 7. $\mathrm{CO}_{2}$ equivalent emissions for absorption cooling project in EU-15 at zero and current carbon price and at carbon prices determining technology switch (labels above the bars). 


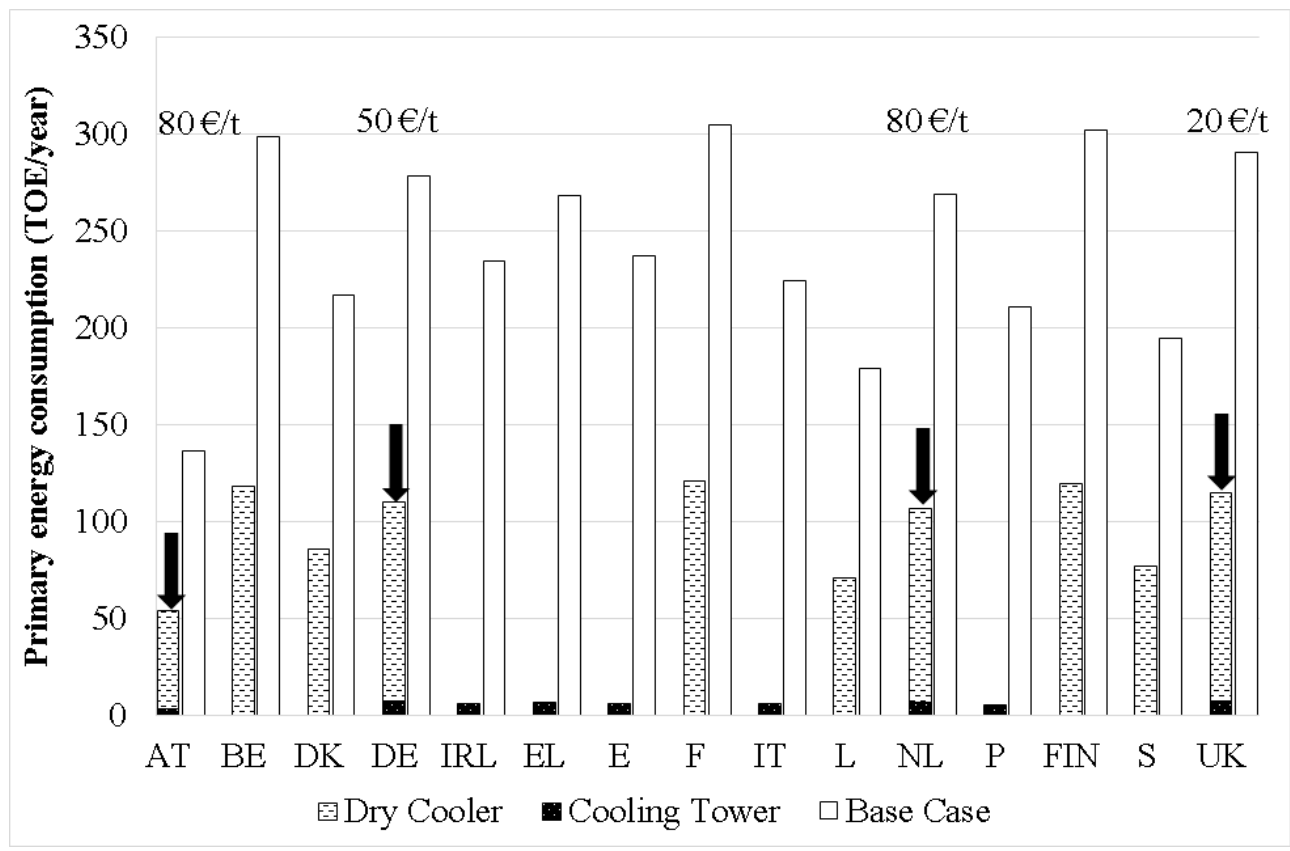

Figure 8. Primary energy consumption for absorption cooling project in EU-15 at zero and current carbon prices and at carbon prices determining technology switch (labels above the bars).

\subsubsection{Power generation with ORC}

Based on the model results, the heat recovery project for electricity generation would be feasible in most countries, with the exception of Finland, Sweden and France, which are characterized by lowest electricity tariffs. Water footprints are reported in Figure 9, $\mathrm{CO}_{2}$ equivalent emissions in Figure 10 and primary energy consumption is represented in Figure 11.

In France, the project configuration (iii) with dry cooling becomes feasible at a carbon price of $80 \mathrm{t} / \mathrm{CO}_{2 \text { eq }}$ (grey label in Figures 9-11), in spite of the relatively modest reduction in carbon emissions. The introduction of waste-heat-to-power technology in France is associated with a more evident decrease in primary energy consumption and indirect water demand, depending on the high nuclear power share in the electricity generation mix. As dry cooling is preferred in France, waste heat recovery is also associated with lower water consumption than the base case (grey arrow in Figures 9-11). The opposite occurs when higher carbon prices induce a switch in cooling systems technologies (black arrows in Figures 9-11). 


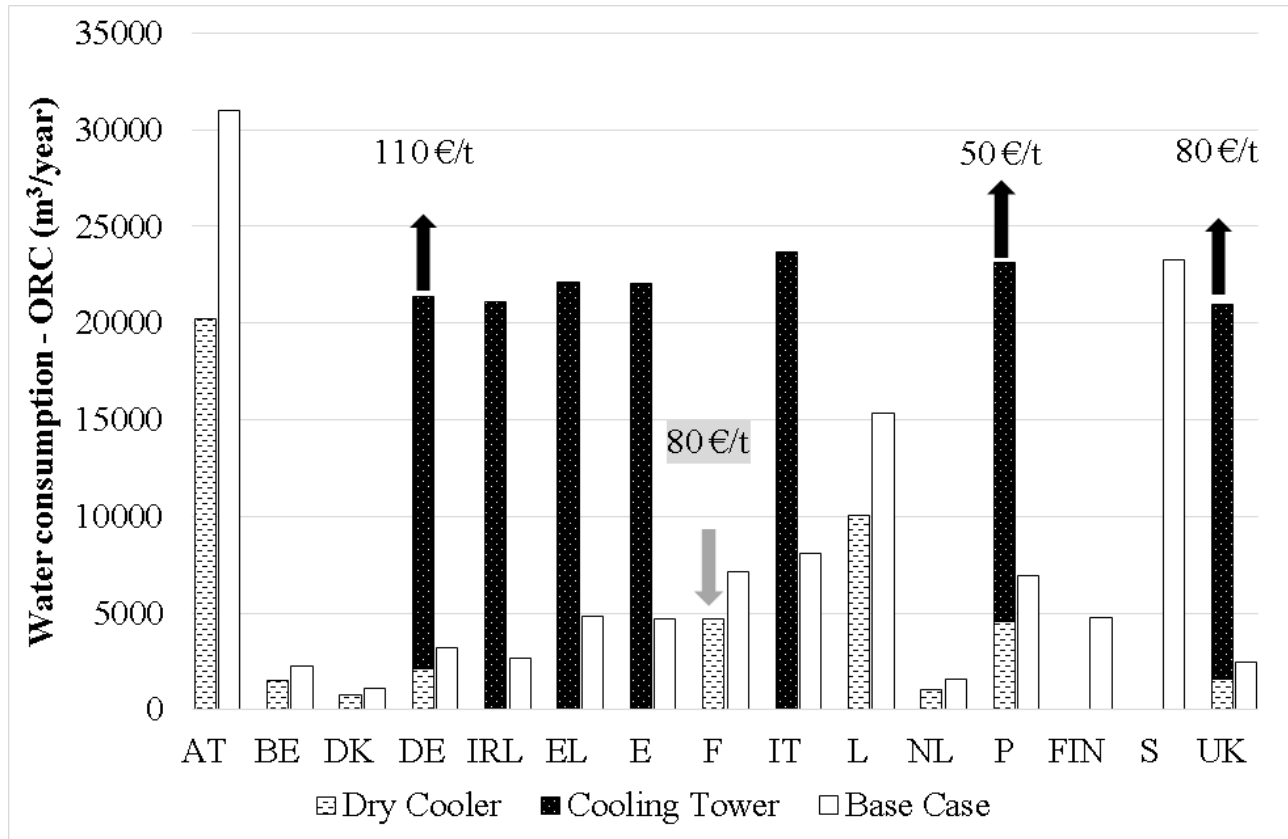

Figure 9. Water consumption for ORC project in EU-15 at zero and current carbon price and at carbon prices determining technology switch (labels above the bars).

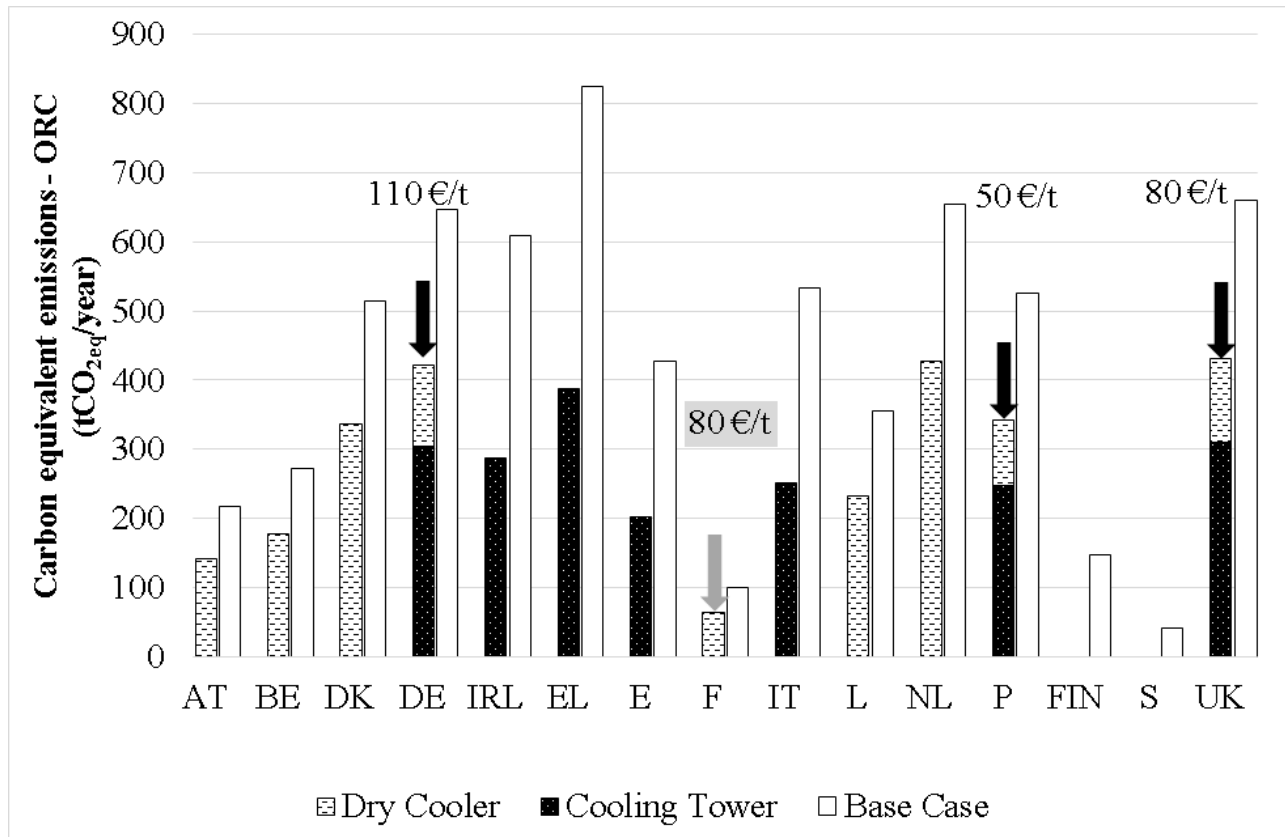

Figure 10. CO2 equivalent emissions for ORC project in EU-15 at zero and current carbon price and at carbon prices determining technology switch (labels above the bars). 


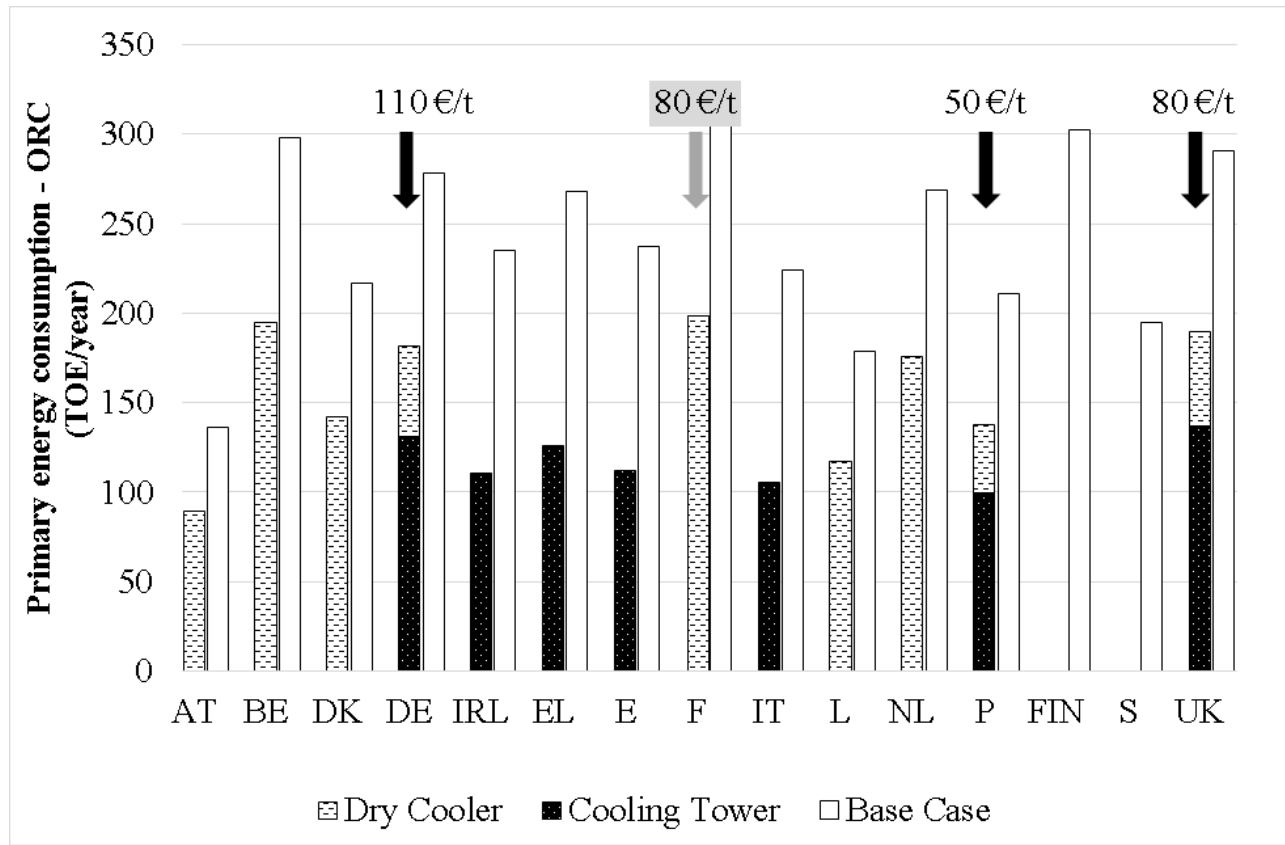

Figure 11. Primary energy consumption for ORC project in EU-15 at null carbon prices and at carbon prices determining technology switch (labels above the bars).

Like in configuration (ii), in Italy, Spain, Ireland and Greece wet cooling is the preferred option, which is associated with somewhat lower water demand than in configuration (ii) (see Figure 9). As clarified in the presentation of the case study, this is mainly due to the fact that wet cooling is only used to dissipate waste heat from the ORC condenser and residual waste heat from hot water circuit, while dry cooling is maintained for dissipation at the condenser of low temperature vapour compression chillers. In general terms, low grade waste heat recovery with ORC would be associated with higher residual heat loads to dissipate than absorption cooling. For ORC, also the ratio between heat loads at cooling systems and the net electricity consumption avoided through waste heat recovery would be less favourable than for absorption cooling.

In Portugal, dry cooling is the preferred option at zero and current carbon price levels, while a switch towards wet cooling happens at $50 € / \mathrm{tCO}_{2}$ eq. Switch prices are higher than in configuration (ii) because the residual heat dissipation capacity required in configuration (iii) is smaller, and so are reductions in carbon emissions (Figure 10) and primary energy consumption (Figure 11) associated with changing cooling systems technologies. The switch from dry to wet cooling systems in Germany, for instance, determines an expected reduction in $\mathrm{CO}_{2 \text { eq }}$ emissions of $120 \mathrm{t} / \mathrm{year}$ and a reduction in primary energy consumption of about $51 \mathrm{TOE} / \mathrm{year}$ : corresponding reductions for configuration (ii) in Germany would be almost 240 tCO2eq $_{\text {year }}$ and about 103 TOE/year, respectively. The shift towards water intensive technologies at higher carbon prices is thus limited to Germany and the UK. 


\section{CONCLUSIONS}

Moving from a case study of low grade waste heat recovery for absorption cooling or for power generation through ORC at an Italian electric steelmaking site subject to EU ETS obligations, a generalization was attempted in that the same project was evaluated in the EU15 countries. The aim of the assessment was to establish the impact of heat recovery projects on $\mathrm{CO} 2$ equivalent emissions and on primary energy and water consumption depending on the associated heat dissipation systems - either based on wet-cooling or dry-cooling - which are shown to be at any rate needed for absorption cooling or power generation alternatives. It was assumed that companies decided for different technologies on a purely economic (lowest expected costs) basis.

Both direct and indirect water consumption were investigated in order to assess whether the water consumption avoided thanks to electricity savings associated with wet cooling system could offset the additional direct consumption by these systems. To this end, a first estimate of national water footprint for electricity generation in the EU-15 has been proposed in this paper. As to the water-energy-GHG nexus at country level, it is found that EU-15 countries with higher carbon and primary energy indicators have significantly lower water consumption indicators, and vice versa, mainly due to hydro-power footprints and shares. This is in line with the most recent findings by [87], who present the challenge of reducing both carbon and water footprint at the same time.

The same challenge applies to industrial heat recovery projects.

In this paper, it has been shown that absorption cooling is a viable technology to exploit low grade waste heat from water cooling systems at a typical electric steelmaking site under the economic conditions applying in all EU-15 countries. Because the EER of absorption chiller is lower than that of vapour compression units, they require comparatively higher cooling loads at dissipation systems, i.e. dry coolers or wet cooling towers, which are balanced by the reduction in cooling loads for waste heat dissipation. Significant reductions in purchased electricity are thus achieved, associated with primary energy savings and carbon emission reduction over the EU-15. However, this study has shown that, depending on local water and electricity prices, as well as on the national energy mix, a technology switch from dry coolers to cooling towers may be the least cost option for the project, which may cause even tenfold increases in the consumptive water footprint of the process. 
This typically happens in countries characterized by low water prices and high electricity prices for industries. Based on model estimates, this has been found to be the case of southern European countries, which by contrast are typically affected by water scarcity.

While the economic performance of different cooling technologies and heat recovery configurations seems to be mainly determined by water and power prices, it has also been shown how technology choice may be affected by policies aimed at carbon emission reduction, which cause a shift towards water intensive technologies for carbon prices of 20 $€ / \mathrm{tCO}_{2}$ and above.

A similar behaviour was demonstrated for low grade waste heat recovery for power generation, obtained with ORCs in this case. In this case, economic feasibility is more importantly affected by incentives, due to high capital costs and limited efficiency of the conversion systems for typical temperatures of waste heat flows. Even in this case, carbon prices may determine a switch towards more water intensive technologies for residual waste heat dissipation.

In spite of common intuition, it has thus been verified that recovering waste heat from cooling systems does not always generate a reduction in the consumptive water footprint of the process in question.

It is thus recommended that analysts evaluating energy efficiency projects in the steelmaking industry, and in process industries on the whole, calculate performance indicators both for energy and water consumption, as well as for carbon equivalent emissions.

It is also recommended that policy makers designing incentives supporting energy efficiency or GHG reduction projects for the industry combine them with constraints, incentives or goals for water consumption reduction, taking a nexus approach.

A limitation of the study is the particular size and shape of the examined solutions and in the fact that climate differences between different countries have not been considered. Further research is being conducted to evaluate these aspects, however it is expected that local climate conditions are even more likely to favour the switch towards absorption cooling systems coupled with cooling towers in southern European countries. An objective of future research is also to investigate further technologies, sizes and waste heat flows could be investigated with this approach.

The present study was also limited by the difficulty in obtaining data, particularly on real costs of water and electricity for industrial customers. Although appropriate tools exist to handle uncertainty, including the Monte Carlo approach used in this work, in our view more accurate results could be the outcome of collaborative research in an international framework, 
which could also link a water-energy-GHG nexus perspective to the investigation of industrial waste heat potentials. Since southern Europe appears the most problematic area, and since our analysis had to be limited to the EU-15 due to the lack in economic data for remaining EU-28 countries, countries located in South-Eastern Europe could be a promising target for future research projects.

\section{NOMENCLATURE}

$\alpha \quad$ intercept for capital cost estimation with linear or constant functions

$\beta \quad$ slope for capital cost estimation with linear functions

$\eta \quad$ electric efficiency of ORC

$\eta_{p} \quad$ pump electric efficiency

$\Delta \mathrm{h} \quad$ circuit head loss $[\mathrm{kPa}]$

a subscript for absorption cooling

c subscript for mechanical vapour compression

$\mathrm{m} \quad$ equipment vs capacity exponent for capital cost estimation with power functions

$\mathrm{r} \quad$ subscript for refrigeration

$\mathrm{p} \quad$ subscript for power generation

BF Blast Furnace

BOF Basic Oxygen Furnace

$\mathrm{C}_{0} \quad$ Capital cost coefficient for cost estimation with power functions

$\mathrm{CO}_{2}$ eq Carbon dioxide equivalent

CT Cooling Tower

DC Dry cooling

EAF Electric Arc Furnace

EER Energy Efficiency Ratio

EER $_{\mathrm{a}} \quad$ Energy Efficiency Ratio of absorption chiller

EER $_{c} \quad$ Energy Efficiency Ratio of compression chiller

EU ETS European Emission Trading Scheme

$\mathrm{L} \quad$ Latent Heat for Vaporization of water $[\mathrm{kJ} / \mathrm{kg}]$

LTC Low Temperature Cooling

MAPE Mean Absolute Percentage Error

MPE Mean Percentage Error

MVC Mechanical Vapour Compression

ORC Organic Rankine Cycle

HR Heat Recovery 
$\mathrm{P}_{0} \quad$ Reference Power output for ORC capital cost estimation with power function [kW]

$\mathrm{P}_{\mathrm{D}} \quad$ Auxiliary power consumption for dry cooling [kW]

$\mathrm{P}_{\mathrm{W}} \quad$ Auxiliary power consumption for wet cooling $[\mathrm{kW}]$

PORC Electric power output of ORC $[\mathrm{kW}]$

$\mathrm{Q}_{0} \quad$ Reference heat dissipation capacity for cooling systems cost estimation [kW]

$\mathrm{Q}_{\mathrm{r}} \quad$ Heat dissipated for condensation in refrigeration cycles [kW]

$\mathrm{Q}_{\mathrm{c}} \quad$ Cooling effect, i.e. heat removed from hot medium by refrigeration cycles [kW]

$\mathrm{Q}_{\mathrm{d}} \quad$ Total waste heat dissipated [kW]

Q $\quad$ Cooling system load $[\mathrm{kW}]$

$\mathrm{Q}_{\mathrm{w}} \quad$ Waste heat from process cooling circuit $[\mathrm{kW}]$

QHRa Total waste heat dissipated with heat recovery for absorption cooling [kW]

$\mathrm{Q}_{\mathrm{p}} \quad$ Heat dissipated for condensation in power generation cycles [kW]

QHRp Total waste heat dissipated with heat recovery for power generation $[\mathrm{kW}]$

QHRiii Total waste heat dissipated with heat recovery for configuration iii $[\mathrm{kW}]$

TOE Tonne of Oil Equivalent

WCD Water Cooling Duct

\section{REFERENCES}

1. Hagebro, C., Cederwall, K.Workshop 7 (synthesis): Integrating the water and energy sectors, Water Science and Technology, 47 (6), pp. 189-191, 2003.

2. U.S. Department of Energy, Energy Demands on Water Resources, Report to Congress on the Interdependency of Energy and Water, United States, Washington D.C., 2006.

3. Dombrowsky I., Water-energy-food - do we need a nexus perspective? The Bonn Nexus Conference, The Current Column, 2011.

4. Schnoor JL. Water-energy nexus, Environmental Science \& Technology, Vol. 45, No. 12, pp. 5065-5065, 2011.

5. Lubega, W.N., Farid, A.M., Quantitative engineering systems modeling and analysis of the energy-water nexus, Applied Energy, Vol. 135, pp. 142-157, 15 December 2014.

6. Fthenakis, D.V., Kim, H.C., Life-cycle uses of water in U.S. electricity generation, Renewable and Sustainable Energy Reviews, Vol. 14, Issue 7, Pages 2039-2048, September 2010.

7. Liu, L., Hejazi, M., Patel, P., Kyle, P., Davies, E., Zhou, Y., Clarke, L., Edmonds, J., Water demands for electricity generation in the U.S.: Modeling different scenarios for the waterenergy nexus, Technological Forecasting and Social Change, Vol. 94, pp. 318-334, May 2015.

8. Liang, S., Zhang, T., Interactions of energy technology development and new energy exploitation with water technology development in China, Energy, Vol. 36, Issue 12, pp. 6960-6966, December 2011. 
9. Feng, K., Hubacek, K., Ling Siu, Y., Li, X., The energy and water nexus in Chinese electricity production: A hybrid life cycle analysis, Renewable and Sustainable Energy Reviews, Vol. 39, pp. 342-355, November 2014.

10. Siddiqi, A., Diaz Anadon, L., The water-energy nexus in Middle East and North Africa, Energy Policy, Vol. 39, Issue 8, pp. 4529-4540, August 2011.

11. Vilanova, M.R.N., Balestieri, J.A.P., Exploring the water-energy nexus in Brazil: The electricity use for water supply, Energy, Vol. 85, pp. 415-432, June 2015.

12. Okadera, T., Chontanawat, J., Gheewala, S. H., Water footprint for energy production and supply in Thailand, Energy, Vol. 77, pp. 49-56, December 2014.

13. Endo, A., Tsurita I., Burnett, K., Orencio, P.M., A review of the current state of research on the water, energy, and food nexus, Journal of Hydrology: Regional Studies, December 2015.

14. Muhammad Wakeel, Bin Chen, Tasawar Hayat, Ahmed Alsaedi, Bashir Ahmad, Energy consumption for water use cycles in different countries: A review, Applied Energy, Vol. 178, 15 September 2016, Pages 868-885

15. Mesfin M. Mekonnen, P. W. Gerbens-Leenes and Arjen Y. Hoekstra, The consumptive water footprint of electricity and heat: a global assessment, Environmental Science: Water Research and Technology. 1, 3, 2015, p. 285-297

16. WWAP (United Nations World Water Assessment Programme). The United Nations World Water Development Report 2015: Water for a Sustainable World. Paris, UNESCO, 2015.

17. Gu, A., Teng, F., Lv, Z., Exploring the nexus between water saving and energy conservation: Insights from industry sector during the 12th Five-Year Plan period in China, Renewable and Sustainable Energy Reviews, Vol. 59, pp. 28-38, June 2016.

18. Walsh, B.P., Murray, S.N., O'Sullivan, D.T.J., The water energy nexus, an ISO50001 water case study and the need for a water value system, Water Resources and Industry, Vol. 10, pp. 15-28, June 2015.

19. Varbanov, P.S., Energy and water interactions: implications for industry, Current Opinion in Chemical Engineering, Vol. 5, pp. 15-21, August 2014.

20. Ahmetović, E., Ibrić, N., Kravanja, Z., Grossmann, I.E., Water and energy integration: A comprehensive literature review of non-isothermal water network synthesis, Computers \& Chemical Engineering, Vol. 82, pp 144-171, November 2015.

21. Tran, T., Da, G., Moreno-Santander, M.A., Vélez-Hernández, G.A., Giraldo-Toro, A., Piyachomkwan, K., Sriroth, K., Dufour, D., A comparison of energy use, water use and carbon footprint of cassava starch production in Thailand, Vietnam and Colombia, Resources, Conservation and Recycling, Vol. 100, pp. 31-40, July 2015.

22. Yoke Kin Wan, Rex T.L. Ng, Denny K.S. Ng, Kathleen B. Aviso, Raymond R. Tan, Fuzzy multi-footprint optimisation (FMFO) for synthesis of a sustainable value chain: Malaysian sago industry, Journal of Cleaner Production, Volume 128, 1 August 2016, Pages 62-76.

23. Ozturk, E., Karaboyaci, M., Yetis, U., Yigit, N.O., Kitis, M. Evaluation of Integrated Pollution Prevention Control in a textile fiber production and dyeing mill, Journal of Cleaner Production, Vol. 88, pp. 116-124, February 2015.

24. Eurostat, Energy Balance Sheet, 2015 edition, ISSN 1830-7558 doi:10.2785/388553.

25. IEA, 2010. World Energy Outlook 2010. Paris.

26. European Union, European Commission, EU ETS Handbook, 2015, avilable at https://ec.europa.eu/clima/sites/clima/files/docs/ets_handbook_en.pdf

27. World Steel Association, Water management in the steel industry, position paper, 2015, ISBN 978-2-930069-81-4

28. Yifan Gu, Jin Xu, Arturo A. Keller, Dazhi Yuan, Yi Li, Bei Zhang, Qianting Weng, Xiaolei Zhang, Ping Deng, Hongtao Wang, Fengting Li, Calculation of water footprint of the iron 
and steel industry: a case study in Eastern China, Journal of Cleaner Production, Volume 92, 1 April 2015, Pages 274-281

29. Maria T. Johansson, Mats Söderström, Options for the Swedish steel industry - Energy efficiency measures and fuel conversion, Energy, Volume 36, Issue 1, January 2011, Pages 191-198.

30. Johansson, M.T., Söderström, M., Electricity generation from low-temperature industrial excess heat - an opportunity for the steel industry, Energy efficiency, Vol. 7(2), pp. 203-215, 2014.

31. José Antonio Moya, Nicolás Pardo, The potential for improvements in energy efficiency and $\mathrm{CO} 2$ emissions in the EU27 iron and steel industry under different payback periods, Journal of Cleaner Production, Volume 52, 1 August 2013, Pages 71-83

32. Fabio Dal Magro, Antonella Meneghetti, Gioacchino Nardin, Stefano Savino, Enhancing energy recovery in the steel industry: Matching continuous charge with off-gas variability smoothing, Energy Conversion and Management, Volume 104, 1 November 2015, Pages 7889

33. Hannu Suopajärvi, Antti Kemppainen, Juho Haapakangas, Timo Fabritius, Extensive review of the opportunities to use biomass-based fuels in iron and steelmaking processes, Journal of Cleaner Production, Volume 148, 1 April 2017, Pages 709-734

34. IEA Clean Coal Centre, CO2 abatement in the iron and steel industry. Profiles 12/1, 2012

35. Ryan J. Klapperich, Daniel J. Stepan, Melanie D. Jensen, Charlie D. Gorecki, Edward N. teadman, John A. Harju, David V. Nakles, Andrea T. McNemar, The Nexus of Water and CCS: A Regional Carbon Sequestration Partnership Perspective, Energy Procedia, Volume 63, 2014, Pages 7162-7172

36. Campana, F., Bianchi, M., Branchini, L., De Pascale A., Peretto, A., Baresi, M., Fermi, A., Rossetti, N., Vescovo, R., ORC waste heat recovery in European energy intensive industries: Energy and GHG savings, Energy Conversion and Management, Vol. 76, pp. 244-252, December 2013.

37. Chan, C.W., Ling-Chin, J., Roskilly, A.P., A review of chemical heat pumps, thermodynamic cycles and thermal energy storage technologies for low grade heat utilisation, Applied Thermal Engineering, Vol. 50(1), pp.1257-1273, May 2013.

38. Viklund, S.B., Johansson, M.T., Technologies for utilization of industrial excess heat: potentials for energy recovery and $\mathrm{CO}_{2}$ emission reduction. Energy Conversion and Management, Vol. 77, pp. 369-379, 2014.

39. Lu, H., Price, L., Zhang, Q. Capturing the invisible resource: Analysis of waste heat potential in Chinese industry, Applied Energy, Vol. 161, pp. 497-511, 2016.

40. Miró, L., Brückner, S., Cabeza, L.F., Mapping and discussing Industrial Waste Heat (IWH) potentials for different countries, Renewable and Sustainable Energy Reviews, Vol. 51, art. no. 4573, pp. 847-855, 2015.

41. Forman, C., Muritala, I., Pardemann, R., Meyer, B., Estimating the global waste heat potential, Renewable and Sustainable Energy Reviews, Vol. 57, pp. 1568-1579, 2016.

42. Pansera G., Griffini N., Dedusting plants for electric arc furnaces, Millennium Steel, pp. 8589, 2016

43. Wang S., Chapter 10, Refrigeration systems: components, in Wang S., Handbook of Air Conditioning and Refrigeration, Second Edition, McGraw Hill, 2000

44. Eicker U., Energy Efficient Buildings with Solar and Geothermal Resources, John Wiley and sons, 2014

45. York technical service, YIA Absorption chiller Engineering guide, Johnson Controls, available at http://www.johnsoncontrols.com/-/media/jci/be/united-states/hvacequipment/chillers/be engguide yia_singleeffect-absorption-chillers-steam-and-hot-waterchillers.pdf , 2017 
46. Systema, Heating, Cooling and Green Energy, Impianti ad assorbimento package e skid (in Italian), available at http://www.systema.it/assets/uploads/Brochure/Catalogo\%20Cooling\%20IT\%20042017\%20Rev.04.pdf , 2017

47. Brückner, S., Liu, S., Miró, L., Radspieler, M., Cabeza, L.F., Lävemann, E., Industrial waste heat recovery technologies: An economic analysis of heat transformation technologies, Applied Energy, Vol. 151, pp. 157-167, August 2015.

48. Vélez, F., Segovia, J.J., Carmen Martín, M., Antolín, G., Chejne, F., Quijano, A., A technical, economical and market review of organic Rankine cycles for the conversion of low-grade heat for power generation, Renewable and Sustainable Energy Reviews, Vol. 16, Issue 6, pp. 4175-4189, August 2012.

49. Pandey, D., Agrawal, M. \& Pandey, J.S. Environmental Monitoring and Assessment Vol 178, Issue 1, pp. 135-160, 2011

50. F. Meunier, Co- and tri-generation contribution to climate change control, Applied Thermal Engineering, Volume 22, Issue 6, April 2002, Pages 703-718

51. Nelson Fumo, Louay M. Chamra, Analysis of combined cooling, heating, and power systems based on source primary energy consumption, Applied Energy, Volume 87, Issue 6, June 2010, Pages 2023-2030

52. LU-VE, AIA Dry coolers and condensers for industrial applications, available at http://manuals.luve.it/Industrial\%20Applications/files/assets/common/downloads/Industrial \%20Applications.pdf, 2017

53. Thermokey, Dry coolers, available at http://www.thermokey.it/pages/allegati/Cataloghi/ThermoKey\%20\%20Dry\%20Cooler_ENG.pdf , 2017

54. Vose, D., Quantitative risk analysis. Guide to Monte Carlo Simulation Modeling, John Wiley and Sons, Chichester, 1996.

55. Hammonds JS, Hoffman FO, Bartell SM. An introductory guide to uncertainty analysis in environmental and health risk assessment. Prepared for Oak Ridge Laboratory for the U.S. Department of Energy, 1994

56. Dale, A.T., Bilec, M.M., The Regional Energy \& Water Supply Scenarios (REWSS) model, Part I: Framework, procedure, and validation, Sustainable Energy Technologies and Assessments, Vol. 7, pp. 227-236, September 2014.

57. Escriva-Bou, A., Lund, J.R., Pulido-Velazquez, M., Modeling residential water and related energy, carbon footprint and costs in California, Environmental Science \& Policy, Vol. 50, pp. 270-281, June 2015.

58. George Caralis, Danae Diakoulaki, Peijin Yang, Zhiqiu Gao, Arthouros Zervos, Kostas Rados, Profitability of wind energy investments in China using a Monte Carlo approach for the treatment of uncertainties, Renewable and Sustainable Energy Reviews, Volume 40, December 2014, Pages 224-236

59. World Bank Database, World Development Indicators: Electricity production, sources, and access, URL: http://wdi.worldbank.org/table/3.7, February 2016.

60. U.S. Energy Information Administration Database, International Energy Statistics, URL: http://www.eia.gov/beta/international/, February 2016.

61. Palisade Corporation, Guide to Using @ RISK, Risk Analysis and Simulation Add-In for Microsoft® Excel, Version 5.5 May, 2009

62. Daniel J. Duffy, Joerg Kienitz, Monte Carlo Frameworks: Building Customisable Highperformance C++ Applications, John Wiley and Sons, 2009

63. Giorgio Locatelli, Mauro Mancini, Small-medium sized nuclear coal and gas power plant: A probabilistic analysis of their financial performances and influence of $\mathrm{CO} 2$ cost, Energy Policy, Volume 38, Issue 10, October 2010, Pages 6360-6374 
64. Xin Li A., Feng, K., Ling Siu, Y., Hubacek, K., Energy-water nexus of wind power in China: The balancing act between $\mathrm{CO}_{2}$ emissions and water consumption, Energy Policy, Vol. 45, pp. 440-448, June 2012.

65. Saidur, B.R., Rahim, N.A., Islam, M.R., Solangi, K.H., Environmental impact of wind energy, Renewable and Sustainable Energy Reviews, Vol. 15, Issue 5, pp. 2423-2430, June 2011.

66. Burkhardt III, C.J.J., Heath, G.A., Turchi, C.S., Life cycle assessment of a parabolic trough concentrating solar power plant and the impacts of key design alternatives, Environmental Science \& Technology, Vol. 45, pp. 2457-2464, 2011.

67. Fthenakis, D.V., Kim, H.C., Life-cycle uses of water in U.S. electricity generation, Renewable and Sustainable Energy Reviews, Vol. 14, Issue 7, Pages 2039-2048, September 2010.

68. Macknick, E.J., Newmark, R., Heath, G., Hallett, K.C., A Review of Operational Water Consumption and Withdrawal Factors for Electricity Generating Technologies, Technical Report NREL/TP-6A20-50900, March 2011.

69. IINAS - Gemis 4.93, http://www.iinas.org/gemis.html, 2016.

70. Hondo, G.H., Life cycle GHG emission analysis of power generation systems: Japanese case, Energy, Vol. 30, Issues 11-12, pp. 2042-2056, 2005.

71. IPCC, 2011: Summary for Policymakers. In: IPCC Special Report on Renewable Energy Sources and Climate Change Mitigation [O. Edenhofer, R. Pichs-Madruga, Y. Sokona, K. Seyboth, P. Matschoss, S. Kadner, T. Zwickel, P. Eickemeier, G. Hansen, Schlömer, C. von Stechow (eds)], Cambridge University Press, Cambridge, United Kingdom and New York, NY, USA.

72. Schlömer S., T. Bruckner, L. Fulton, E. Hertwich, A. McKinnon, D. Perczyk, J. Roy, R. Schaeffer, R. Sims, P. Smith, and R. Wiser, 2014: Annex III: Technology-specific cost and performance parameters. In: Climate Change 2014: Mitigation of Climate Change. Contribution of Working Group III to the Fifth Assessment Report of the Intergovernmental Panel on Climate Change [Edenhofer, O., R. Pichs-Madruga, Y. Sokona, E. Farahani, S. Kadner, K. Seyboth, A. Adler, I. Baum, S. Brunner, P.Eickemeier, B. Kriemann, J. Savolainen, S. Schlömer, C. von Stechow, T. Zwickel and J.C. Minx (eds.)]. Cambridge University Press, Cambridge, United Kingdom and New York, NY, USA.

73. Wilby, R.M., Rodríguez González, A.B., Vinagre Díaz, J.J., Empirical and dynamic primary energy factors, Energy, Vol. 73, pp. 771-779, August 2014.

74. Deru, M., Torcellini. P., Source Energy and Emission Factors for Energy Use in Buildings, Technical Report NREL/TP-550-38617, Revised June 2007.

75. EVAPCO, Operation and Maintenance Instructions for For EVAPCO Induced Draft and Forced Draft Closed Circuit Coolers and Evaporative Condensers, available at http://www.evapco.eu/sites/evapco.eu/files/white_papers/evapco_maintenance_instructions coolers_condensers_om bulletin_116-e_0416_2.pdf, 2017

76. Max S Peters, Klaus D Timmerhaus, Ronald E. West, Plant Design and Economics for Chemical Engineers, McGraw-Hill Education, 5th edition, 2003

77. Tchanche, B.F., Pétrissans, M., Papadakis, G., Heat resources and organic Rankine cycle machines, Renewable and Sustainable Energy Reviews, Vol. 39, pp. 1185-1199, 2014.

78. Eurostat Database, Energy Price Statistics, Source : Statistics Explained URL: http://ec.europa.eu/eurostat/statistics-explained/, February 2016.

79. Lallana C., Indicator Fact Sheet Water Prices, EEA, http://www.eea.europa.eu/data-andmaps/indicators/water-prices, 2003.

80. OECD, Environment at a Glance 2013: OECD Indicators, OECD Publishing, Paris. DOI: http://dx.doi.org/10.1787/9789264185715-en, 2013. 
81. Lauruschkus F., Meermann K., Bürger K., Albrecht H., A comparison of European water and wastewater costs, BDEW, 2015.

82. Statista, Water

Price,

URL: http://de.statista.com/statistik/daten/studie/184203/umfrage/kosten-fuer-trinkwasser-undabwasser-in-deutschland/, February 2016.

83. Water Supply and sanitation in the Republic of Ireland , URL: https://en.wikipedia.org/wiki/Water_supply_and_sanitation_in_the_Republic_of_Ireland\#Ta riffs, February 2016.

84. OECD, OECD Environmental Performance Reviews: Greece 2009, OECD Publishing, Paris. DOI: http://dx.doi.org/10.1787/9789264061330-en, 2010.

85. Ville De Luxembourg, Industrial Water Tariff, http://www.vdl.lu/Citoyens+et+r\%C3\%A9sidents/Energies_+Eaux+et+Canalisation/Eaux/T arification.html, February 2016.

86. European Environment Agency - EEA, $\mathrm{CO}_{2}$ equivalent emissions for electricity in EU-28, http://www.eea.europa.eu/data-and-maps/figures/co2-electricity-g-per-kwh/co2-perelectricity-kwh-fig-1_2010_qa.xls, February 2016.

87. Mesfin M. Mekonnen, P.W. Gerbens-Leenes, Arjen Y. Hoekstra, Future electricity: The challenge of reducing both carbon and water footprint, Science of The Total Environment, Volumes 569-570, 1 November 2016

88. Croci E., Voluntary Agreements for $\mathrm{CO} 2$ Emissions Reduction: Evaluation and Perspectives, Energy \& Environment 2003 14:5, 663-676

89. Volker H. Hoffmann, EU ETS and Investment Decisions:: The Case of the German Electricity Industry, European Management Journal, Volume 25, Issue 6, December 2007, Pages 464-474 